\title{
EFICIÊNCIA E AUTONOMIA ESCOLAR: EVIDÊNCIAS PARA O PERÍODO 2007-2013
}

\author{
Victor Rodrigues de Oliveira * \\ Wallace Patrick Santos de Farias Souza ${ }^{\dagger}$ \\ Ana Cláudia Annegues $\ddagger$
}

\begin{abstract}
Resumo
O objetivo deste estudo é mensurar a eficiência das escolas públicas brasileiras e os condicionantes do seu grau de eficiência no período 20072013. Realizou-se um procedimento em três estágios: um estimador não paramétrico adequado à presença de outliers, o desconto da não discricionariedade e um método de regressão quantílica com censura. Encontrouse que a autonomia escolar assume um papel pouco relevante no processo de gestão das escolas.
\end{abstract}

Palavras-chave: Eficiência; Outliers; Autonomia

\begin{abstract}
The aim of this study is to measure the efficiency of Brazilian public schools and the conditions of its efficiency in the period 2007-2013. This was a procedure in three stages: a nonparametric estimator suitable to the presence of outliers, discounting the non-discretionary and quantile regression method with censoring. We found that school autonomy plays a minor role in school management process.
\end{abstract}

Keywords: Efficiency; Outliers; Autonomy.

JEL classification: I21, D61, C21

DOI: http://dx.doi.org/10.11606/1980-5330/ea155952

\footnotetext{
* Professor do Departamento de Economia - Universidade Federal do Paraná. E-mail: victor5491@gmail.com

† Professor do PPGE - Universidade Federal da Paraíba. E-mail: wpsfarias@gmail.com

‡ Doutoranda em Economia Aplicada do PPGE - Universidade Federal do Rio Grande do Sul.

E-mail: annegues.ana@gmail.com
} 


\section{Introdução}

A educação pode impedir ou ampliar as oportunidades econômicas e sociais dos indivíduos ao longo do seu ciclo de vida, uma vez que um ensino de baixa/alta qualidade pode reforçar a estrutura na qual os mesmos estão inseridos. Como ressaltado por Hanushek \& Woessmann (2008), a busca por um sistema de ensino de alta qualidade é um objetivo de todas as sociedades, dado que as diferenças de qualidade na educação permitem explicar além do efeito positivo na remuneração do trabalho oriunda dos ganhos de produtividade, as diferenças, dentre outras, nos níveis de saúde, de criminalidade e de participação política entre os países.

Quando se observa a situação do ensino no Brasil nota-se que muitas reformas como a adoção de políticas redistributivas e transformações na organização e gestão da educação pública ${ }^{1}$ ocorreram nas últimas décadas, visando melhorar a excelência da educação e ampliar o acesso à escolaridade. Entretanto, essas ações não foram suficientes para promover uma educação de qualidade devido à ineficiência na aplicação dos recursos, gerando perda de economias de escala.

A despeito do processo de universalização da educação básica e fundamental no Brasil, as deficiências do sistema educacional ainda persistem. De acordo com Gramani \& Duarte (2011), de 1995 a 2007 os indicadores quantitativos apresentaram evolução considerável com um aumento do percentual de crianças entre 7 e 14 anos que frequentavam a escola de $93 \%$ para $98 \%$, na faixa de 15 a 17 anos subiram de $64 \%$ para $80 \%$ e a taxa de conclusão do ensino médio elevou-se de $17 \%$ para $44 \%$. Todavia, a qualidade do ensino aproximada por testes padronizados nacionais e internacionais deixa a desejar. Os resultados obtidos a partir do Programme for International Student Assessment (PISA) indicaram que dos 31 países avaliados em 2000, o Brasil estava na última posição do ranking nos exames de leitura e de matemática. Em 2009, dos 65 países analisados, o Brasil figurava entre os países com piores proficiências em matemática ( $58^{\mathrm{a}}$ posição) e em leitura ( $54^{\mathrm{a}}$ posição). Esses resultados indicam que a questão da qualidade do ensino no Brasil merece atenção e, portanto, a compreensão dos determinantes do desempenho dos alunos é fundamental para o desenvolvimento de ações e programas que objetivem melhorar a educação. Nesse sentido, é importante que se avalie como os insumos educacionais são administrados pela escola. Isto é, dado que os recursos são escassos, é fundamental que o seu uso promova o máximo de benefício social.

É relevante compreender o impacto da educação sobre o crescimento econômico. No tocante a esse assunto, Hanushek \& Woessmann (2008) comparam os efeitos da quantidade e da qualidade da educação sobre a taxa de crescimento do PIB per capita. Os resultados indicam que um aumento de um desvio-padrão da quantidade da educação, mensurada pela média dos anos de escolaridade da população, eleva o PIB per capita em 0,26\% ao ano. Em contraste, o mesmo aumento de um desvio-padrão da qualidade da educação, medido pelo resultado no teste de proficiência em matemática, pode elevar o PIB per capita em 1,4\% ao ano. Apesar dos resultados obtidos pelos autores

\footnotetext{
${ }^{1}$ Entre as principais transformações do ensino público brasileiro incluem a descentralização dos recursos educacionais concomitantemente à expansão das matrículas a partir de 1996, que culminaram na criação do FUNDEF (Fundo de Desenvolvimento do Ensino Fundamental e de Valorização do Magistério).
} 
ainda se conhece pouco sobre as melhores maneiras de promover ganhos no sistema de ensino.

Como destacado por (Delgado \& Machado 2007, p. 427), quando se confrontam os exames internacionais em educação e o mercado de trabalho observa-se que a qualificação dos alunos no Brasil está abaixo de muitos países em desenvolvimento, sendo ainda considerado um país de baixo nível educacional. Nessa direção, cabe mencionar os resultados obtidos junto a (OCDE 2011, p. 4). Segundo esse relatório "escolas que gozam de maior autonomia na alocação de recursos tendem a mostrar melhor desempenho dos alunos do que aquelas com menor autonomia". Esse resultado reforça a necessidade de aumentar a proximidade entre a população e os responsáveis pela elaboração das políticas públicas, que resulta em uma menor assimetria de informações entre esses agentes e tem por objetivo elevar o desempenho educacional (eficácia) e melhorar a gerência do sistema de ensino público (eficiência).

Um dos eixos temáticos da nova problemática da política educacional brasileira está relacionado à capacidade dos programas de acccountability ${ }^{2}$ induzirem mudanças efetivas na qualidade do ensino. Especificamente, a área de atuação da escola deve aumentar, de forma que a avaliação da adequação dos recursos educacionais deve começar na própria escola por meio da análise da eficiência das mesmas. Isto não significa eliminar os demais indicadores de qualidade educacional, mas sim ampliar os mecanismos de avaliação da gestão educacional pública brasileira a partir do ambiente escolar.

Com base nesse critério, é notório o descompasso existente entre os recursos disponíveis e os resultados alcançados pelas escolas na otimização dos seus indicadores. Por conseguinte, acredita-se que para alcançar maior eficiência dos recursos em educação é necessário estimular a formulação de políticas educacionais que envolvam estratégias eficientes de gestão e de financiamento que incluam as escolas, o que pode permitir alcançar a expansão qualitativa da educação e uma maior equidade social. Nesse sentido, este estudo objetiva mensurar a eficiência das escolas públicas brasileiras e compreender quais os fatores que a afetam, de forma a contribuir para a formulação de políticas mais específicas para o setor educacional.

Em primeiro lugar, a eficiência das escolas é mensurada por meio da técnica não paramétrica order- $\alpha$ proposta por Aragon et al. (2005). Esse método confere um papel relevante aos outliers no conjunto de dados e assim é possível caracterizar a presença de escolas "supereficientes" na amostra. Algumas escolas com menores níveis de insumos, por exemplo, podem administrar de forma mais eficiente os recursos à sua disposição vis-à-vis escolas com um alto nível de insumos. Cabe ressaltar que as estratégias adotadas pela literatura, em sua grande maioria, visam eliminar ou reduzir a influência dos outliers, o que conduz à perda de uma grande base informacional. A adoção desse estimador se justifica por não ter sido aplicado ainda ao caso brasileiro em nenhuma análise empírica sobre educação ou outros temas correlatos e, assim, permitir a caracterização adequada do grau de eficiência das escolas.

\footnotetext{
${ }^{2}$ Observe que as políticas de accountability podem levar a uma piora na dinâmica do sistema de ensino no que diz respeito à repetência e ao abandono. A necessidade de cumprir as metas de desempenho acaba punindo os alunos em pior situação, que, ou são retidos pelos professores, ou evadem ao perceber que irão falhar. Assim, essas políticas devem investir em procedimentos de prevenção do insucesso, visto que a retenção e a promoção social (ou automática) falham tanto na perseguição das metas, quanto na provisão de equidade.
} 
Em segundo lugar, serão descontadas do cálculo da eficiência as características relacionadas ao corpo discente, isto é, o background familiar e as características dos alunos. Como mostrado por Afonso \& Aubyn (2005), as variáveis que não estão sob o controle direto das escolas, chamadas de nãodiscricionárias, têm um impacto significativo sobre os escores finais de eficiência. Assim, aquelas escolas que têm alunos cujos pais apresentam um alto nível educacional, de forma geral, terão melhores desempenhos em exames padronizados como a Prova Brasil e o SAEB em relação àquelas com menor nível de capital humano. Como as medidas de eficiência utilizadas não estão definidas em um intervalo fechado, como o estimador DEA (Análise Envoltória de Dados) que varia no intervalo entre zero e um, não é possível utilizar um modelo Tobit, como em Delgado \& Machado (2007) e Gonçalves \& França (2013). Uma estratégia simples para o cálculo da medida de eficiência adequada é regredir o escore de eficiência contra as variáveis não discricionárias por meio do método de painel de dados. O resíduo dessa regressão representa a medida de eficiência ajustada.

Após a obtenção dos escores de eficiência ajustados, será utilizado um modelo de dados em painel no contexto de regressão quantílica, para avaliar quais os impactos das características das escolas sobre os diversos níveis de eficiência da gestão escolar. Nessa última etapa, também se considera o fato do escore de eficiência ajustado ser censurado.

Para cumprir o objetivo proposto, utilizaram-se os microdados da Prova Brasil para os anos de 2007, 2009, 2011 e 2013. Desse modo, é possível compreender a dinâmica da gestão escolar ao longo dos últimos anos, ao contrário da literatura nacional que realizou análises pontuais. A avaliação da eficiência gerencial ${ }^{3}$ no âmbito da escola permite que se caracterize a autonomia da administração escolar e se investigue quais os determinantes dos resultados alcançados.

O artigo apresenta a seguinte estrutura, além desta introdução. A seção seguinte traz um resumo das evidências empíricas nacionais e internacionais presentes na literatura. Na Seção 3, são destrinchados todos os passos da execução empírica, bem como o método não paramétrico de mensuração da eficiência e o modelo de dados em painel. A Seção 4 contém a descrição do banco de dados utilizado e a caracterização da amostra. Em seguida, são apresentados os resultados encontrados. E por fim, na Seção 6 são feitas as considerações finais.

\section{Literatura Empírica}

A mensuração da eficiência da alocação dos recursos públicos é necessária porque os agentes econômicos têm a percepção de que os recursos nem sempre são utilizados da melhor maneira. A crença de que o setor público gasta muito e não consegue resolver os problemas da sociedade brasileira trouxe à discussão a necessidade de maior eficiência na aplicação desses recursos e suscitou a adoção de técnicas para avaliar se o direcionamento dos gastos atende a esse objetivo, com destaque para o setor educacional. Estudos recentes têm avaliado e questionado a compensação dos esforços que têm sido despendidos

\footnotetext{
${ }^{3}$ Representa a real capacidade do diretor em promover a melhor combinação entre os recursos disponíveis e os objetivos propostos, retirando-se o efeito de variáveis que não estão sob o controle do gestor.
} 
pelas autoridades públicas para alcançar a universalização e a eficiência do ensino público. A Tabela 1 apresenta um resumo de algumas dessas pesquisas, relatando as amostras e as metodologias empregadas, bem como os resultados encontrados. Em geral, as evidências sugerem uma inadequada gestão pública dos recursos.

Um modelo bastante utilizado é a DEA, que permite verificar se os recursos orçamentários, por exemplo, estão sendo utilizados de forma que se reflitam na melhoria da educação, da saúde, dentre outros. Os trabalhos que utilizam essa metodologia, em geral, sugerem que a eficiência educacional não está relacionada à quantidade de recursos, mas à maneira que esses recursos são aplicados. Esses resultados também são encontrados quando se utilizam outros métodos, como a Análise Envoltória de Dados livre de Convexidade $(\mathrm{FDH})^{4}$. No entanto, de acordo com Faria et al. (2008), uma localidade pode aplicar bem os seus recursos e mesmo assim não conseguir atingir bons indicadores sociais porque os gastos não são suficientes para atingir os melhores resultados.

A literatura internacional sobre eficiência é muito ampla, merecendo destaque os trabalhos de Gupta \& Verhoeven (2001), de Clements (2002), de Afonso \& Aubyn (2005, 2006), de Castano \& Cabanda (2007), de Afonso \& Fernandes (2008), de Afonso et al. (2010) e de Cherchye et al. (2010). Gupta \& Verhoeven (2001) avaliam a eficiência das despesas públicas em educação e saúde em trinta e sete países africanos no período entre 1984 e 1995 . Os resultados mostraram que, em média, os países da África são menos eficientes do que os países da Ásia e do hemisfério ocidental. Todavia, os gastos em educação e saúde tornaram-se mais eficientes durante o período analisado. A avaliação sugere ainda que as melhorias no nível educacional e nos serviços de saúde nos países africanos exigem mais do que aumentos do orçamento público. Clements (2002) mostrou que a redução da ineficiência em alguns países da OCDE deve ocorrer por meio do aumento dos gastos em educação.

No Brasil, em comparação com a literatura internacional, são poucos os estudos sobre eficiência, ainda em menor número os que se aplicam à educação. Entre eles é possível destacar os estudos de Marinho et al. (1997) e de Marinho \& Façanha (1999) que avaliam a eficiência das instituições de ensino superior; de Sousa \& Ramos (1999), de Faria et al. (2008) e de Machado Junior et al. (2011) que investigam a eficiência dos gastos municipais em geral; de Almeida \& Gasparini (2011) que avaliam a oferta de serviços educacionais; e de Delgado \& Machado (2007) e de Gonçalves \& França (2013) que analisam a eficiência das escolas por meio de variantes da técnica DEA.

Marinho \& Façanha (1999) avaliaram o modelo de gestão e alocação de recursos do Ministério da Educação e Cultura (MEC) para aplicação nas instituições de ensino superior no ano de 1994. Os autores demonstraram que a eficiência dessas é mal avaliada pelo MEC, o que colaborou para um alto grau de desigualdade na alocação de recursos. Além disso, observou-se que sem mudanças de regras de alocação e de avaliação, algum aprimoramento imediato poderia ser alcançado por meio de um modelo que estabelecesse mecanismos sistemáticos de avaliação e de distribuição de recursos.

Ao perceberem o baixo número de indicadores para avaliar as despesas públicas na Paraíba, Almeida \& Gasparini (2011) criaram um índice a partir da metodologia DEA para examinar a relação entre o desempenho educacional

\footnotetext{
${ }^{4}$ Do inglês Free Disposal Hull.
} 
Tabela 1: Principais estudos sobre eficiência em gastos públicos com educação

\begin{tabular}{|c|c|c|c|}
\hline Autor & Amostra & Metodologia & Conclusão \\
\hline $\begin{array}{l}\text { Afonso \& Aubyn } \\
(2005)\end{array}$ & Países da OCDE (2000) & DEA e FDH & $\begin{array}{l}\text { Japão, Coreia do Sul e Suécia são os únicos países eficientes } \\
\text { na alocação de recursos para a saúde e a educação. }\end{array}$ \\
\hline $\begin{array}{l}\text { Afonso \& Aubyn } \\
(2006)\end{array}$ & Painel de 25 países (2003) & $\begin{array}{l}\text { Modelo semipara- } \\
\text { métrico }\end{array}$ & $\begin{array}{l}\text { A ineficiência está fortemente relacionada com o PIB per ca- } \\
\text { pita e o nível educacional dos adultos. }\end{array}$ \\
\hline $\begin{array}{l}\text { Cherchye et al. } \\
(2010)\end{array}$ & $\begin{array}{l}\text { Escolas públicas e privadas de Flanders } \\
\text { (Bélgica) (2003-2004 e 2004-2005) }\end{array}$ & Estimador order- $m$ & $\begin{array}{l}\text { Melhores condições de renda dos alunos e maiores níveis de } \\
\text { proficiência em matemática e em leitura estão associadas a } \\
\text { maiores escores de eficiência. }\end{array}$ \\
\hline Thieme et al. (2013) & Chile (2008) & $\begin{array}{l}\text { Abordagem de fron- } \\
\text { teira parcial e estru- } \\
\text { tura multinível }\end{array}$ & $\begin{array}{l}\text { Considerando apenas as variáveis relacionadas aos estudan- } \\
\text { tes, há um alto grau de ineficiência. Com o modelo completo, } \\
\text { o principal responsável pela ineficiência da escola é a dota- } \\
\text { ção de recursos. }\end{array}$ \\
\hline Faria et al. (2008) & Municípios fluminenses (1990-2000) & DEA & $\begin{array}{l}\text { A eficiência não está relacionada à disponibilidade maior ou } \\
\text { menor de recursos, mas sim a melhores resultados das políti- } \\
\text { cas públicas. }\end{array}$ \\
\hline $\begin{array}{l}\text { Machado Junior } \\
\text { et al. }(2011)\end{array}$ & Municípios cearenses (2005) & DEA & $\begin{array}{l}\text { Os gastos públicos em educação apresentaram os menores es- } \\
\text { cores de eficiência técnica, revelando a inadequada alocação } \\
\text { dos recursos, o que contribuiu para a perda de economias de } \\
\text { escala. }\end{array}$ \\
\hline $\begin{array}{l}\text { Carvalho \& Sousa } \\
(2014)\end{array}$ & Região Nordeste e Sudeste (2007) & $\begin{array}{l}\text { DEA e fronteira es- } \\
\text { tocástica }\end{array}$ & $\begin{array}{l}\text { Encontraram que mesmo descontados os fatores ambientais } \\
\text { e aleatórios, ainda existe uma ineficiência atribuída à gestão. }\end{array}$ \\
\hline
\end{tabular}

Fonte: Elaborado pelos autores. 
dos alunos no ensino fundamental frente aos recursos utilizados e os respectivos custos para se atingir tal meta. Os resultados indicaram um baixo número de municípios eficientes, apenas $28,5 \%$, e observou-se que as cidades menos eficientes se concentraram no sertão paraibano. Isso forneceu evidências de que as políticas educacionais nessa mesorregião precisam ser mais discutidas.

Um dos principais trabalhos sobre eficiência escolar e seus determinantes é o estudo de Delgado \& Machado (2007). Os autores procuraram avaliar a eficiência nas escolas públicas estaduais mineiras, empregando o método DEA para os anos de 2002 e de 2003. Os resultados obtidos no trabalho de Delgado \& Machado (2007) mostraram, de maneira geral, que as escolas selecionadas como eficientes proveem ensino de melhor qualidade a um custo relativamente menor do que as outras escolas. Segundo os autores, os principais determinantes da eficiência estão associados ao background familiar, entre eles, a escolaridade da mãe, o estímulo à leitura e o hábito de estudo. Todavia, não foi retirada a influência das variáveis não discricionárias sobre as medidas de eficiência.

Em um artigo recente, Gonçalves \& França (2013) investigaram os determinantes da eficiência municipal na gestão educacional brasileira a partir de um modelo em três estágios que contempla o ajuste para as variáveis nãodiscricionárias. Considerando o processo de descentralização da educação básica, os dados para 2005 revelaram que há baixa correlação entre eficácia e eficiência e que muitas capitais consideradas pouco eficazes apresentam níveis de eficiência elevados no uso dos recursos. A análise do modelo de misturas finitas indicou que um dos principais objetivos da descentralização, que é o aumento da transparência no uso dos recursos com impactos positivos sobre a eficiência, logrou resultados positivos desde que aplicados em ambientes mais democráticos. O principal resultado indicou a necessidade de uma maior intervenção governamental por meio de mecanismos de responsabilização política, além de um maior aporte de recursos.

Carvalho \& Sousa (2014) mensuraram a eficiência para as escolas públicas do Nordeste e do Sudeste do Brasil com dados da prova Brasil 2007, por meio de análise envoltória de dados em três estágios, seguindo a estratégia desenvolvida por Fried et al. (2002), que combina o método DEA e a abordagem de fronteira estocástica. As autoras concluíram que existe a necessidade de melhorias na gestão escolar dada a sua ineficiência, mesmo descontando os fatores ambientais e aleatórios, para os quais as escolas não têm controle.

Para países desenvolvidos, Hattie (2009) tratou da influência da estrutura escolar no aprendizado e verificou que a maior diferença está dentro das escolas e não entre escolas. Isso é consistente com o fato de que nesses países a infraestrutura se apresenta de forma equitativa entre as escolas, diferente de países em desenvolvimento como o Brasil, onde as responsabilidades são divididas entre estados e munícipios e predominam grandes desigualdades regionais.

São poucos os trabalhos que adotam a escola como unidade de análise, limitando-se ao universo de escolas pertencente a alguma cidade ou no máximo a algum estado, tal como Delgado \& Machado (2007). Ao mesmo tempo, a inclusão apenas de insumos e produtos gerenciados pela escola na medida de eficiência pode distorcer o desempenho observado, pois pode-se estar atribuindo toda responsabilidade aos gestores por diferenças ambientais, econômicas, de acesso, culturais, institucionais e outras que a gestão escolar não tem controle. 
No entanto, devido ao problema da dimensionalidade, estudos têm combinado a metodologia DEA com técnicas econométricas, adotando uma análise em dois ou mais estágios (Ruggiero 1998, Banker \& Natarajan 2008). O trabalho de Carvalho \& Sousa (2014) vai além e utiliza uma abordagem em três estágios. A metodologia DEA é utilizada no primeiro estágio e o método de fronteira estocástica no segundo, com vistas a captar o componente assimétrico do termo de erro que corresponde à ineficiência gerencial e um componente simétrico (ruído estatístico), tendo uma fronteira melhor definida.

Dito isso, o presente estudo se assemelha ao de Carvalho \& Sousa (2014) por considerar uma estratégia em três estágios, porém diferencia-se ao utilizar um estimador quantílico para o cômputo da eficiência, que como já mencionado permite a inclusão de unidades ditas "supereficientes", além de tratar recorrer a um painel de escolas, permitindo abranger um período maior de tempo.

A partir do exposto acima se observa que há um volume crescente de estudos que mensuram a eficiência dos gastos públicos em educação, principalmente no âmbito internacional. Todavia, são poucos os que avaliaram a eficiência ao nível da escola, isto é, que investigaram os recursos que são administrados diretamente pela escola, como proposto por Delgado \& Machado (2007) ou os que avaliam a eficiência considerando um conjunto de variáveis relacionadas aos municípios, tal qual realizado por Gonçalves \& França (2013). Porém, estes últimos estudos empregaram diversos métodos para eliminar ou mitigar a presença de outliers, como a inspeção manual ou métodos de reamostragem do tipo bootstrap e jackknife, por exemplo. Dessa forma, ocorre uma perda de informações relevantes a respeito das escolas mais ou menos eficientes.

\section{Estratégia Empírica}

\subsection{Primeiro Estágio: Eficiência Produtiva}

A despeito da ampla literatura que discute a qualidade da educação e a sua importância para a promoção do crescimento econômico, ainda se conhece pouco sobre as formas de efetivamente melhorá-la. Para alcançar esse objetivo é importante o conhecimento da fronteira de eficiência na educação (FEE) apresentada inicialmente por Coleman et al. (1966). A partir do relatório Coleman ${ }^{5}$ houve uma expansão do número de estudos que procuram compreender como as diversas características dos alunos, das escolas e das famílias se combinam para determinar o desempenho dos alunos. No âmbito dos insumos educacionais comparam-se, de forma geral, os resultados dos testes padronizados com os insumos dos professores, dos alunos e das turmas (Hanushek 1986, Hanushek \& Luque 2003, Delgado \& Machado 2007) e com as características dos municípios (Gonçalves \& França 2013).

\footnotetext{
${ }^{5} \mathrm{Em} 1966$ foi realizado nos Estados Unidos uma grande pesquisa sobre educação promovido pelo Office of Education. James Coleman, sociólogo, foi designado pelo congresso americano para investigar as escolas americanas que recebiam alunos de diferentes raças no país. A priori acreditava-se que as desigualdades educacionais poderiam ser reduzidas por meio de intervenções governamentais. Os resultados surpreendentes revelaram que o principal responsável por essas desigualdades seria o background familiar e, assim, as escolas teriam um papel muito reduzido nesse processo.
} 
A mensuração da FEE constitui uma das etapas mais importantes para a formulação de políticas públicas. Para tanto, considere a seguinte função como especificada abaixo:

$$
y_{i}=f\left(x_{i}, b_{i}, d_{i}\right)
$$

em que $y_{i}$ é o rendimento dos alunos na escola $i, x_{i}$ são os insumos educacionais disponibilizados pela escola, $b_{i}$ é o background familiar médio por escola e $d_{i}$ representam as "dotações". Os estudos de Hanushek (1986) e de Hanushek \& Luque (2003) partem do pressuposto de que a função de produção, como especificada pela Equação (1), representa um ajuste ideal para os valores médios da distribuição da variável dependente e, portanto, a estimação correta dessa função deve passar pela média condicional $E(Y \mid X)$. Assim, na média as observações são eficientes, ou seja, situam-se sobre a fronteira de produção. Dessa forma, pode-se incorporar a ineficência na fronteira de produção por meio de um índice $\gamma_{i}$ que multiplica a Equação (1) como segue:

$$
y_{i}=\gamma_{i} f\left(x_{i}, b_{i}, d_{i}\right)
$$

Há duas formas de estimar a Equação (2) (Daraio \& Simar 2007). A partir de um enfoque paramétrico considera-se que os erros seguem uma distribuição normal truncada, conhecido como fronteiras estocásticas ${ }^{6}$. Sob essa abordagem o erro é decomposto em duas partes: a dos erros normais $\left(v_{i}\right)$ e a dos erros não negativos $\left(u_{i}\right)$. Assim, pode-se reescrever essa equação da seguinte forma:

$$
\ln \left(y_{i}\right)=x_{i} \beta+v_{i}+u_{i},
$$

em que $\ln \left(y_{i}\right)$ representa o logaritmo do produto, $x_{i}$ representa os insumos, $v_{i}$ representa os erros aleatórios de acordo com uma distribuição normal e $u_{i}$ representa os erros não positivos a partir de uma normal truncada ou de uma exponencial. Para obter-se o escore de eficiência procede-se uma transformação sobre os erros não positivos, como por exemplo, $\exp \left(u_{i}\right)$.

Contudo, essa abordagem é criticada por confiar em suposições restritivas relativas à forma funcional e à distribuição dos erros aleatórios e por permitir somente um único produto. Nesse sentido, a literatura tem migrado para os métodos não paramétricos que não utilizam os erros aleatórios. Duas técnicas têm sido amplamente utilizadas: a DEA proposta por Charnes et al. (1978) e o Free Disposal Hull proposto por Deprins et al. (1984). O estimador FDH, utilizado neste estudo, afasta-se do pressuposto de convexidade, diferentemente da DEA, e baseia-se na hipótese de dominância fraca.

No entanto, as técnicas não paramétricas também são criticadas por serem determinísticas, vulneráveis à presença de outliers e a erros de mensuração, mas mitigam o fenômeno conhecido como curse of dimensionality, isto é, a perda de qualidade das estimativas à medida que o número de covariadas cresce. Sob a égide desses problemas a literatura que adota estimadores não paramétricos vem deslocando-se para o chamado enfoque de fronteira parcial (partial frontier approach), no qual se pode destacar dois métodos: a análise de eficiência order-m (Cazals et al. 2002) e a order- $\alpha$ (Aragon et al. 2005). A

\footnotetext{
${ }^{6}$ Para uma apresentação detalhada desse método ver Aigner \& Chu (1968), Aigner et al. (1977) e Greene (1993).
} 
principal vantagem dessas análises "parciais" é permitir que observações "supereficientes" sejam alocadas além da fronteira de possibilidade de produção, o que torna as medidas de eficiência menos vulneráveis aos outliers.

Para compreender esse método considere uma amostra composta por $N$ unidades de tomada de decisão (decision making units - DMU). Para cada DMU, $i=1, \ldots, N$, estão relacionados um conjunto de insumos produtivos $x_{i 1}, \ldots, x_{i K}$ e um conjunto de produtos $y_{i 1}, \ldots, y_{i L}$. O principal objetivo de uma medida de eficiência é calcular um escore $\gamma_{i}$ para cada DMU e possibilitar o ranqueamento das mesmas. Normalmente, duas variantes são calculadas: i) a eficiência orientada para os insumos $\gamma_{i}^{i n p}$, isto é, o fator pelo qual o consumo de insumos da DMU $i$ pode ser reduzido proporcionalmente sem alterar o produto resultante; e ii) a eficiência orientada para o produto $\gamma_{i}^{\text {out }}$, onde a geração do produto pode ser aumentada sem alteração do consumo dos insumos. Para os modelos full frontier (DEA e FDH, por exemplo) todas as DMUs são "envelopadas" pela fronteira de possibilidade de produção, isto é, $\gamma_{i}^{i n p} \in(0,1]$ e $\gamma_{i}^{\text {out }} \in[1, \infty)$. Neste artigo, os resultados principais serão todos orientados para os produtos, uma vez que se pretende obter resultados voltados para maximizar os produtos, mas manter o consumo atual dos insumos.

O método order- $\alpha^{7}$ proposto por Aragon et al. (2005) representa uma generalização do estimador FDH. Seja um espaço de probabilidade $(\Omega, \mathcal{A}, P)$ sobre o qual o vetor de insumos $X$ e o vetor de produtos $Y$ estão definidos. Nesse enfoque definem-se o conjunto $\Psi$ no qual estão contidos os vetores de insumos e de produtos, a distribuição conjunta dos dois vetores e um subconjunto de $\Psi$ definido por $\Psi^{*}=\left\{(x, y) \in \Psi \mid F_{X}(x)>0\right\}$. A partir dessa definição o valor da função de produção coincide com o último ponto de um quantil qualquer, isto é, dado que $X \leq x$ tem-se que a seguinte relação deve ser válida:

$$
q_{1}(x)=\inf \{y \geq 0 \mid F(y \mid x)=1\} .
$$

A Equação (4) sugere introduzir o conceito de função de produção de ordem contínua como uma função quantílica de ordem $\alpha, \alpha \in[0,1]$, da função que determina $Y$ dado que $X$ não excede um certo nível de insumos. Assim, tem-se para um determinado nível de insumos $x$, o seguinte valor:

$$
q_{\alpha}(x)=F^{-1}(\alpha \mid x)=\inf \{y \geq 0 \mid F(y \mid x) \geq \alpha\} .
$$

Essa função quantílica condicional é o threshold do produto educacional que é excedido por $100(1-\alpha) \%$ das escolas que utilizam menos insumos do que o nível $x$. Assumindo que para todo $x$ tal que $F_{X}(x)>0$, a função de distribuição condicional $F(\cdot \mid x)$ é estritamente crescente no intervalo $[0, \psi(x)]$. Então,

$$
\forall(x, y) \in \Psi^{*} \text { tem-se que } y=q_{\alpha}(x) \operatorname{com} \alpha=F(y \mid x) .
$$

Ou seja, qualquer plano de produção $(x, y)$ no subconjunto $\Psi^{*}$ pertence a alguma curva quantílica de ordem $\alpha$. Assim, a função quantílica $q_{\alpha}$ mensura a eficiência do plano de produção $(x, y)$ ao compará-lo com todos que utilizam o mesmo nível de insumos $x$, bem como com os que usam níveis menores que $x$. A partir disso, o escore de eficiência é dado por:

\footnotetext{
${ }^{7}$ Aragon et al. (2005) apresentam um tratamento detalhado das propriedades assintóticas desse estimador.
} 


$$
\widehat{\gamma}_{\alpha, i t}^{O A}=P(100-\alpha)\left\{\max _{k=1, \ldots, K}\left\{\frac{x_{k j}}{x_{k i}}\right\}\right\} .
$$

Este estudo adotará o método proposto por Aragon et al. (2005) por três motivos, a saber: i) ainda não foi aplicado ao caso brasileiro e pode gerar informações novas às evidências já conhecidas sobre eficiência educacional; ii) a determinação do número de escolas "supereficientes" é endógena e, portanto, não é necessário determinar a priori a proporção de escolas que se situam além da fronteira de produção; e iii) como apresentado por Daouia \& Ruiz-Gazen (2006), esse estimador é mais robusto à presença de outliers do que o estimador order-m.

A Tabela 2 contém os insumos e os produtos utilizados no cálculo dos escores de eficiência. Foram escolhidos como indicadores de produto as notas médias em Matemática e em Língua Portuguesa e a taxa média de aprovação para cada escola participante da Prova Brasil. A escolha das proficiências segue uma tendência da literatura de nos últimos anos em utilizar notas em exames padronizados como medidas de resultado, como em Almeida \& Gasparini (2011), os quais também trabalharam com as notas da Prova Brasil. A taxa média de aprovação consiste em outro indicador de resultado normalmente empregado pela literatura (Zoghbi et al. 2011), e está ligado a outros resultados que as escolas desejam obter, como a redução dos índices de evasão escolar e de defasagem, além de indicar, em boa parte das vezes, a evolução do processo de aprendizagem dos alunos. A maximização conjunta dessas variáveis é o objetivo do gestor escolar, isto é, tentar fornecer um ensino de qualidade com os melhores resultados em testes padronizados e maior taxa de aprovação possível (reduzir, indiretamente, as taxas de defasagem idadesérie e de evasão escolar).

Em relação às variáveis de insumo, temos indicadores relacionados aos recursos humanos da escola, que são o total de funcionários, o total de alunos, o percentual de professores com ensino superior, se o diretor possui mais de seis anos de experiência no cargo, um indicador da infraestrutura física da escola e a disponibilidade de salas para o ensino. O número total de funcionários representa parte significativa dos orçamentos das escolas no Brasil (Farenzena 2005) e em alguns casos pode significar possíveis fontes de ineficiência gerencial. O percentual de professores com ensino superior atua diretamente na consecução dos resultados das proficiências. A literatura que trata dos determinantes do rendimento escolar apresenta algumas evidências que apontam a influência da formação superior dos professores, tal como (Machado et al. 2013). A experiência do diretor também contribui para a geração de resultados de proficiência (ver Oliveira et al. 2015).

Analogamente ao total de funcionários, a infraestrutura também representa um ponto importante dos orçamentos das escolas e impacta positivamente os resultados dos testes padronizados, como já enfatizado por Oliveira et al. (2015). Muitos trabalhos têm considerado a infraestrutura escolar como um dos aspectos importantes para promoção do resultado na educação brasileira, tal como Castro \& Fletcher (1986) que discutiram as condições materiais das escolas e mostraram a relevância da infraestrutura das escolas para o aprendizado dos alunos, focando ainda sobre questões de eficiência e eficácia dos gastos públicos com educação. Em outro trabalho, Soares et al. (2006) in- 
Tabela 2: Descrição dos insumos e produtos

\begin{tabular}{|c|c|c|}
\hline Variável & Descrição & Fonte \\
\hline \multicolumn{3}{|c|}{ Insumos } \\
\hline Salas de aula & $\begin{array}{l}\text { Número de salas } \\
\text { de aula existen- } \\
\text { tes na escola }\end{array}$ & Censo Escolar \\
\hline Funcionários & $\begin{array}{l}\text { Total de funcio- } \\
\text { nários da escola* }\end{array}$ & Censo Escolar \\
\hline Matrículas & $\begin{array}{l}\text { Total de alunos } \\
\text { da escola }\end{array}$ & Censo Escolar \\
\hline \multirow[t]{3}{*}{ Escolaridade } & $\begin{array}{l}\begin{array}{l}\text { Percentual de } \\
\text { professores }\end{array}\end{array}$ & Censo Escolar \\
\hline & com educação & \\
\hline & $\begin{array}{l}\text { superior na } \\
\text { escola }\end{array}$ & \\
\hline Infraestrutura & $\begin{array}{l}\text { Indicador da es- } \\
\text { trutura física da } \\
\text { escola** }^{* *}\end{array}$ & Censo Escolar \\
\hline Experiência & $\begin{array}{l}\text { Indica se o di- } \\
\text { retor possui seis } \\
\text { anos ou mais de } \\
\text { experiência }\end{array}$ & Censo Escolar \\
\hline \multicolumn{3}{|c|}{ Produtos } \\
\hline Matemática & $\begin{array}{l}\text { Média por escola } \\
\text { da nota dos alu- } \\
\text { nos na prova de } \\
\text { Matemática }\end{array}$ & Prova Brasil \\
\hline Português & $\begin{array}{l}\text { Média por es- } \\
\text { cola da nota } \\
\text { dos alunos na } \\
\text { prova de Língua } \\
\text { Portuguesa }\end{array}$ & Prova Brasil \\
\hline Aprovação & $\begin{array}{l}\text { Taxa média } \\
\text { de aprovação } \\
\text { de alunos por } \\
\text { escola }\end{array}$ & Prova Brasil \\
\hline
\end{tabular}

${ }^{*}$ Inclusive profissionais escolares em sala de aula.

**A construção desse indicador é apresentada na Seção 4.

Fonte: Elaborado pelos autores.

cluíram a infraestrutura escolar como fator importante para explicar os baixos resultados da educação na área rural.

\subsection{Segundo Estágio: Variáveis Não Discricionárias}

Nesta seção, apresenta-se o modelo utilizado para retirar o efeito das variáveis não discricionárias, isto é, expurgar os efeitos que a escola não tem autonomia para controlar sobre a medida de eficiência. Para tanto, utilizou-se um modelo de dados em painel. Essa etapa é fundamental para a correta identificação do grau de eficiência da gestão escolar.

A estratégia para a obtenção de escores robustos consiste na retirada dos efeitos indiretos, relacionados às características dos alunos, que não estão sob o controle das escolas. Desse modo, estima-se um modelo de dados em painel e procede-se o teste de Hausman para avaliar qual a melhor especificação, se um modelo de efeitos fixos ou de efeitos aleatórios. Esse modelo linear com efeito individual não observado, $c_{i}$, é representado abaixo: 


$$
y_{i t}=x_{i t}^{\prime} \delta+c_{i}+u_{i t}
$$

em que $y_{i t}$ é a medida de eficiência técnica, $\mathbf{x}_{i t}$ é o conjunto de variáveis explicativas e $\delta$ é o vetor de parâmetros a ser estimado.

O regressando será a medida de eficiência da gestão escolar obtida por meio do estimador order- $\alpha$ como apresentado na Equação (7) e os regressores são as variáveis não discricionárias apresentadas na Tabela 3.

Tabela 3: Descrição das variáveis não discricionárias

\begin{tabular}{|c|c|c|}
\hline Variável & Descrição & Fonte \\
\hline Homem & Proporção de alunos do sexo masculino & Prova Brasil \\
\hline Branco & $\begin{array}{l}\text { Proporção de alunos que se autodeclara- } \\
\text { ram brancos }\end{array}$ & Prova Brasil \\
\hline Idade & Idade média do aluno & Prova Brasil \\
\hline Mãe & $\begin{array}{l}\text { Proporção de alunos que mora com as } \\
\text { mães }\end{array}$ & Prova Brasil \\
\hline Mãe com superior & $\begin{array}{l}\text { Proporção de alunos que tem mãe com } \\
\text { ensino superior completo }\end{array}$ & Prova Brasil \\
\hline Socioeconômico & Índice de condições financeiras do aluno & Prova Brasil \\
\hline Incentivo escolar & $\begin{array}{l}\text { Indice de incentivo e envolvimento dos } \\
\text { pais na vida escolar }\end{array}$ & Prova Brasil \\
\hline Creche & $\begin{array}{l}\text { Proporção de alunos que iniciaram a tra- } \\
\text { jetória escolar na creche }\end{array}$ & Prova Brasil \\
\hline
\end{tabular}

Segundo Soares \& Collares (2006), a condição familiar teria efeito direto, mas também indireto sobre a proficiência e outros resultados acadêmicos ao possibilitar, por exemplo, a aquisição de bens culturais. E afirmam:

a família primeiro conquista os recursos econômicos; a seguir, (...) algumas (...) adquirem bens culturais; tendo essas duas condições, dedicam tempo para acompanhar a vida escolar de seus filhos. (...) Refletindo o ambiente favorável da casa, os estudantes desenvolvem melhor atitude em relação à escola. Tudo isto resulta em maior proficiência (...).

No que tange a esse respeito, Leon \& Menezes-Filho (2002) já demonstraram que a presença da mãe é relevante na chance de progresso escolar dos filhos e, em menor grau, na qualidade educacional. De forma geral, essa variável é um dos fatores-chave responsáveis pelo sucesso da criança em uma situação de vulnerabilidade social como a pobreza. Além disso, em geral, pais altamente educados podem decidir investir mais do seu tempo e energia na educação dos seus filhos ou eles podem escolher interagir suas atividades diárias com os seus filhos de forma a ajudá-los a serem bem sucedidos na escola. Ao mesmo tempo, famílias com melhores condições socioeconômicas geralmente serão capazes de proporcionar mais recursos educacionais em casa ou de escolher as escolas que irão fornecer-lhes esses recursos. A partir dos microdados do PISA, Afonso \& Aubyn $(2005,2006)$ encontraram evidências de que as variáveis relacionadas às famílias dos alunos representam um dos principais determinantes do desempenho escolar. Gonçalves \& França (2013) também destacaram a importância dessas variáveis ao mostrarem que municípios 
com escolas que possuem um maior estoque de capital humano poderão ter melhores desempenhos nos testes padronizados de avaliação.

Conforme apontado no relatório do Banco Mundial (2001), estudos sobre experiências internacionais trazem evidências de que os cuidados na primeira infância são fatores relevantes na determinação de melhores condições de nutrição e saúde; de melhor desempenho em testes de inteligência; de maior taxa de atendimento escolar; de menor taxa de repetência; de menor taxa de evasão; e ainda maior participação das mulheres na força de trabalho. Desse mesmo relatório constam estimações, para dados do Brasil, do impacto da pré-escola sobre o desempenho escolar, participação no mercado de trabalho e condições de saúde. Os resultados significativos encontrados são de efeito positivo sobre a escolaridade média, redução de repetência, aumento da probabilidade de conclusão das etapas de ensino e aumento do rendimento futuro dos homens. Desse modo, esses fatores foram incluídos nessa segunda etapa empírica.

O resíduo obtido representará a nova medida de eficiência "livre" da influência das variáveis não discricionárias - eficiência gerencial. A medida de eficiência resultante não pode ser interpretada diretamente. Os resíduos obtidos podem apresentar valores positivos ou negativos e faz-se necessário aplicar um método de correção sobre estes. Para tanto, é adotada a estratégia de Gonçalves \& França (2013) e aplicado o método de correção de Greene, cujo procedimento visa subtrair de todos os resíduos o maior valor positivo. Como todos os valores do resíduo tornam-se não positivos, a aplicação do antilog sobre os resultados os tornará não negativos, passando a refletir a eficiência da gestão escolar e, assim, eles não estarão relacionados a qualquer variável não discricionária.

\subsection{Terceiro estágio: Determinantes da Eficiência Gerencial}

Nesta seção, apresenta-se a estratégia empírica para avaliar os determinantes da eficiência gerencial das escolas. A literatura sobre educação tem mostrado que não há uma clara relação entre autonomia na alocação de recursos e desempenho no nível de país. Isso deve acontecer porque a forma como os recursos são distribuídos tende a beneficiar algumas escolas, mas não necessariamente afeta o desempenho do sistema como um todo. Isso reforça a necessidade de se investigar como a autonomia na gestão dos fatores escolares se traduz em eficiência gerencial. É relevante compreender em que medida a participação da comunidade e uma maior autonomia gerencial influenciam a eficiência na utilização dos insumos escolares. Por conseguinte, as variáveis utilizadas nessa etapa estão apresentadas na Tabela 4.

Para cumprir esse objetivo é estimado um painel de efeitos fixos no contexto de regressão quantílica. Todavia, após a correção do termo de erro da Equação (8), a nova medida de eficiência é censurada. Desse modo, adotouse a proposta de Chernozhukov \& Hong (2011). O método proposto pelos autores é um algoritmo em três passos com uma restrição de separação sobre a probabilidade de censura. O estimador é assintoticamente eficiente. Ao mesmo tempo, ele é simples e computacionalmente pouco intensivo. Além disso, tem a vantagem de apresentar uma boa performance em amostras de tamanho pequeno ou modelos com muitas variáveis explicativas.

O estimador de interesse é obtido como segue: 
Tabela 4: Descrição dos determinantes da eficiência gerencial

\begin{tabular}{|c|c|c|}
\hline Variável & Descrição & Fonte \\
\hline Diretoria & $\begin{array}{l}\text { Indica se obteve a direção da escola por meio } \\
\text { de processo seletivo }\end{array}$ & Prova Brasil \\
\hline Conselho & $\begin{array}{l}\text { Indica se o conselho escolar se reuniu três ve- } \\
\text { zes ou mais no ano }\end{array}$ & Prova Brasil \\
\hline Projeto & $\begin{array}{l}\text { Indica se foi elaborado por toda comunidade } \\
\text { escolar }\end{array}$ & Prova Brasil \\
\hline Admissão & $\begin{array}{l}\text { Se o critério de seleção da escola foi o local } \\
\text { de moradia }\end{array}$ & Prova Brasil \\
\hline Interferência & Se há interferência na gestão do diretor & Prova Brasil \\
\hline Livro & Se escolheram o livro didático & Prova Brasil \\
\hline Apoio & Se há apoio da comunidade escolar & Prova Brasil \\
\hline Turma & $\begin{array}{l}4 \text { variáveis dummy indicando os critérios } \\
\text { de formação das turmas, a saber: homo- } \\
\text { geneidade quanto à idade, homogeneidade } \\
\text { quanto ao rendimento escolar, heteroge- } \\
\text { neidade quanto à idade, heterogeneidade } \\
\text { quanto ao rendimento escolar }\end{array}$ & Prova Brasil \\
\hline
\end{tabular}

Fonte: Elaborado pelos autores com base nos microdados da Prova Brasil/INEP.

1. Estime um modelo de probabilidade

$$
\omega_{i t}=p\left(\dot{X}_{i t} \varphi\right)+\varepsilon_{i t},
$$

em que $\omega_{i t}$ é uma variável indicadora de não censura, $p(\cdot)$ denota uma função qualquer e $\dot{X}$ indica transformações de $\left(X_{i t}, C_{i t}\right)$, com $C$ sendo o ponto de censura ${ }^{8}$.

A partir disso, selecione a amostra $J_{0}=\left\{i, t: p\left(\dot{X}_{i t} \widehat{\varphi}\right)>1-\tau+c\right\}$, em que $0<c<\tau$.

2. Obtenha os estimadores iniciais (ineficientes) $\widehat{\beta}_{0}(\tau)$ por meio de uma regressão quantílica

$$
\min _{\beta} \sum_{i \in J_{0}} \sum_{t \in T} \rho_{\tau}\left(y_{i t}-x_{i t}^{\prime} \beta\right)
$$

A partir disso, selecione a amostra $J_{1}=\left\{i, t: x_{i t}^{\prime} \widehat{\beta}_{0}(\tau)>C_{i t}+\zeta_{n}\right\}$, em que $\zeta$ é um número positivo e pequeno, tal que $\zeta_{n} \searrow 0$.

3. Estime novamente a Equação (10) com $J_{1}$ e obtenha os novos valores de $\widehat{\beta}_{1}(\tau)$.

\section{Base de Dados e Estatísticas Descritivas}

Foram empregados os microdados da Prova Brasil para os anos de 2007, 2009, 2011 e 2013 e do Censo Escolar para o mesmo período, considerando-se somente as escolas públicas. A Prova Brasil, iniciada em 2005, trata-se de uma avaliação censitária envolvendo os alunos da $4^{\mathrm{a}}$ série $\left(5^{\circ}\right.$ ano) e $8^{\mathrm{a}}$ série $\left(9^{\circ}\right.$

\footnotetext{
${ }^{8}$ Utilizaram-se funções polinomiais de segundo grau.
} 
ano) do ensino fundamental das escolas públicas das redes municipal, estadual e federal ${ }^{9}$, com o objetivo de avaliar a qualidade do ensino ministrado. Participam dessa avaliação as escolas que possuem, no mínimo, 20 alunos matriculados nas séries/anos avaliados, sendo os resultados disponibilizados por escola e por ente federativo. O cômputo do desempenho dos alunos é baseado nas escalas de proficiência. A proficiência dos alunos corresponde a escalas específicas ao assunto, permitindo avaliar as competências adquiridas pelos alunos ao longo da trajetória escolar. Essas escalas são construídas por meio da Teoria de Resposta ao Item (TRI) e do modelo de Blocos Incompletos Balanceados (BIB).

A TRI é um conjunto de modelos matemáticos que procuram representar a probabilidade de um indivíduo dar uma determinada resposta a um item como função dos parâmetros deste e da habilidade (ou habilidades) do respondente. Essa relação é sempre expressa de tal forma que quanto maior a habilidade, maior a probabilidade de acerto no item. O BIB corresponde, por seu turno, a um esquema otimizado para o rodízio de blocos. A utilização da TRI e do BIB permite, assim, a construção de uma escala para cada disciplina, englobando as duas séries avaliadas e ordenando o desempenho dos alunos do nível mais baixo para o mais alto.

O Censo Escolar, por sua vez, é um levantamento de dados estatísticoeducacionais de âmbito nacional realizado todos os anos com a participação de todas as escolas públicas e privadas do país. O Censo Escolar coleta dados sobre estabelecimentos, matrículas, funções dos docentes, movimento e rendimento escolar.

A partir dos dados primários foram construídos os indicadores de qualidade escolar, um índice socioeconômico do aluno ${ }^{10}$ e um índice de incentivo escolar por meio da técnica de análise de componentes principais para dados categóricos. Para tanto, seguiu-se a abordagem desenvolvida por Niitsuma \& Okada (2005). Assim, considere um conjunto de variáveis de categóricas $z_{1}, z_{2}, \ldots, z_{J}$. Para a $i$-ésima instância $z_{i}$ assume o valor $z_{i a}$, que é representado pelo vetor das coordenadas dos vértices $\mathbf{v}^{k_{i}}\left(z_{i a}\right)$. Concatenando todas as variáveis categóricas, temos:

$$
\mathbf{z}(a)=\left(\mathbf{v}^{k_{1}}\left(z_{1 a}\right), \mathbf{v}^{k_{2}}\left(z_{2 a}\right), \ldots, \mathbf{v}^{k_{J}}\left(z_{J a}\right)\right) .
$$

Assim, os indicadores podem ser obtidos por meio da seguinte covariância:

$$
\mathcal{A}=\frac{1}{N} \sum_{a=1}^{N}(\mathbf{z}(a)-\overline{\mathbf{z}})^{\top}(\mathbf{z}(a)-\overline{\mathbf{z}}),
$$

em que $\overline{\mathbf{z}}=\frac{1}{N} \sum_{a=1}^{N} \mathbf{z}(a)$

Para o indicador socioeconômico foram consideradas as seguintes variáveis do questionário do aluno: o número de aparelhos de televisão $(0,1,2$ ou mais); o número de geladeiras ( $0,1,2$ ou mais); o número de carros $(0,1,2,3$ ou mais); se há computador; o número de dormitórios ( $0,1,2,3$ ou mais); o

\footnotetext{
${ }^{9}$ Estas últimas foram excluídas da amostra, pois elas possuem critérios de ingresso baseados em desempenho, diferentemente da maioria das outras escolas públicas.

${ }^{10}$ Este se faz necessário uma vez que não existem informações referentes ao nível de renda da família do aluno.
} 
número de empregada(s) doméstica(s) pelo menos cinco dias por semana $(0$, 1, 2, 3 ou mais).

Por sua vez, o índice de incentivo escolar é construído com base nas seguintes variáveis: se os pais do aluno o incentivam a estudar; se os pais do aluno o incentivam a fazer o dever de casa; se os pais do aluno o incentivam a ler; se os pais do aluno o incentivam a não faltar às aulas; e se os pais do aluno conversam sobre o que acontece na escola.

Por fim, o indicador de qualidade da escola é baseado no seguinte conjunto de variáveis: se a escola tem rede pública de abastecimento de água; se a escola tem rede pública de energia elétrica; se a escola tem rede pública de esgoto; se a escola tem coleta periódica de lixo; se há sala de professores; se há sala de diretor; se há sala de informática; se há laboratório de ciências; se há cozinha; se há biblioteca; se há banheiros na escola (dependências externa e interna); e se há acesso de alunos a computadores.

A amostra desse trabalho é restrita às escolas que participaram dos quatro anos consecutivos da Prova Brasil e cujos alunos fizeram as provas de Língua Portuguesa e de Matemática ${ }^{11}$.

As Tabelas 5 e $6,4^{\text {a }}$ série e $8^{\text {a }}$ série, respectivamente, apresentam um conjunto de estatísticas descritivas, que permitem caracterizar o comportamento dos insumos e produtos utilizados no processo de estimação da eficiência gerencial das unidades escolares para cada ano do painel. Com relação aos produtos, observa-se que houve um aumento modesto no desempenho médio nas provas de Matemática e de Língua Portuguesa, porém para a $8^{a}$ série há uma queda na proficiência média de Matemática. No tocante à taxa de aprovação por escola, para a $4^{\text {a }}$ série há manutenção desse indicador. Todavia, para a fase final do ensino fundamental nota-se o aumento da taxa de reprovação dos alunos.

Por sua vez, as variáveis que representam os insumos utilizados mostram um comportamento interessante. Há uma menor disponibilidade de salas de aula para ensino, menor número de funcionários que atendem a escola, redução do número de alunos matriculados por estabelecimento de ensino, queda da proporção de professores com ensino superior completo e piora do indicador de infraestrutura escolar. Apenas a proporção de diretores com seis anos ou mais de experiência na função apresentou uma taxa de crescimento positivo entre 2007 e 2013.

Isto posto, tem-se pouca melhoria dos indicadores qualitativos e piora de um indicador quantitativo. E associado a esse resultado tem-se uma situação de deterioração e redução dos recursos escolares. A combinação desses fatores permite explicar, em certo grau, as evidências empíricas de baixa qualidade do ensino público brasileiro.

Também é interessante investigar como os insumos estão correlacionados entre si (e o mesmo para os produtos) e qual a direção da associação entre os recursos escolares e os produtos. A matriz de correlação está apresentada na Tabela 7. Todas as medidas de associação linear foram estatisticamente significativas e positivas, com exceção para a relação entre o desempenho médio em Português e a medida de experiência dos professores. Depreende-se que há uma relação de moderada a alta para os insumos e o mesmo é válido para os produtos. Quando se cruzam os diversos insumos e produtos, os resultados

\footnotetext{
${ }^{11}$ Os valores dos quantis ótimos para o cômputo da medida de eficiência para os anos de 2007, 2009, 2011 e 2013 são, respectivamente, 95.23, 94.18, 97.15 e 95.50.
} 
mostram que a experiência dos diretores e o número de matrículas por escola, que indica a escala na qual a unidade escolar opera, apresentaram baixa correlação com os indicadores de produtos utilizados. Por seu turno, as medidas de qualificação profissional dos docentes e de qualidade da estrutura física escolar evidenciaram um maior grau de correlação com os produtos.

Nas Tabelas 8 e 9 constam informações no que tange às variáveis não discricionárias. A amostra deste estudo é caracterizada por uma maior presença de alunos do sexo feminino (em torno de $51 \%$ para $4^{\text {a }}$ série e $55 \%$ para a $8^{\text {a }}$ série). Um dado importante é a redução gradual de alunos que se autodeclararam brancos, representando $25 \%$ e $15 \%$ do total de alunos em 2013 para a $4^{\mathrm{a}}$ série e a $8^{\mathrm{a}}$ série, respectivamente.

Quanto à evolução, observa-se redução nas escolas de: alunos que moram com a mãe (principalmente a $8^{\mathrm{a}}$ série) e do percentual de mães com ensino superior (de $32 \%$ para $10 \%$ para a $4^{\text {a }}$ série e de $15 \%$ para $10 \%$ no caso da $8^{\text {a }}$ série). Apesar disso, as estatísticas também expõem que houve ganhos nas condições financeiras das famílias dos alunos: o índice socioeconômico foi, em média, de 0,42 em 2007 para 0,47 em 2013 para os anos iniciais do ensino fundamental (representando uma elevação de 11,91\%); para a fase final dessa etapa de ensino, o índice aumentou de 0,36 para 0,45, o que se traduz em um ganho de $25 \%$, em média, nas condições de vida dos alunos. Esse indicador é relevante já que crianças de famílias pobres, devido a causas como pais com baixa escolaridade e piores condições de moradia e nutrição, têm maior dificuldade na escola, levando a maiores taxas de reprovação, de evasão e de abandono escolar. Portanto, esses elementos irão se combinar para determinar parte dos resultados em testes padronizados. Por sua vez, não houve alterações relevantes no índice que mensura o envolvimento dos pais com a vida escolar do filho e que reflete o incentivo aos estudos e à leitura e com o que acontece no ambiente escolar. Desse modo, houve expansão de recursos econômicos para as famílias dos alunos, porém sem ganhos de capital humano das mães ou elevação indireta do capital cultural.

Com relação aos alunos que iniciaram sua trajetória escolar na creche, observa-se que para a 4a série houve uma pequena expansão entre 2007 e 2013 e uma redução de quase $27 \%$ para a $8^{a}$ série. A qualidade das creches estaria diretamente relacionada à qualidade das atividades e à estrutura do programa educacional, cujo impacto é considerável no desenvolvimento da criança. $\mathrm{O}$ relatório do Banco Mundial (2001), supracitado, mostrou a importância da oferta desse serviço. Todavia, o estudo de Barros et al. (2011) encontrou que o baixo padrão dos mesmos também poderia ser capaz de comprometer o desempenho educacional futuro dos alunos. Assim, o efeito de iniciar a vida escolar na creche sobre o desempenho acadêmico futuro dos alunos estaria diretamente relacionado à qualidade do projeto pedagógico oferecido nessa fase $^{12}$. E, portanto, o efeito creche pode atuar no sentido de reforçar ou piorar a performance dos alunos.

No tocante aos determinantes da eficiência gerencial, as Tabelas 10 e 11 mostram a adoção de várias medidas de autonomia escolar e sua evolução ao longo do período 2007-2013, separadamente por série do ensino fundamental.

A variável diretoria indica se o diretor assumiu o cargo exclusivamente por

\footnotetext{
${ }^{12}$ Os autores mostraram que a qualidade da creche pode ser medida de diversas maneiras, e que cada uma dessas medidas pode ter diferentes custos e impactos também distintos para o desenvolvimento infantil.
} 
Tabela 5: Estatísticas descritivas dos insumos e produtos - $4^{\text {a }}$ série

\begin{tabular}{lrrrrrrrr}
\hline \multicolumn{7}{c}{2007} & \multicolumn{3}{c}{2009} \\
\hline Variáveis & Média & Desvio Padrão & Mínimo & Máximo & Média & Desvio Padrão & Mínimo & Máximo \\
\hline Salas de aula & 12,310 & 5,769 & 4,000 & 72,000 & 11,640 & 5,806 & 2,000 & 68,000 \\
Funcionários & 56,320 & 29,720 & 15,000 & 129,000 & 54,030 & 30,360 & 2,000 & 153,000 \\
Matrículas & 794,300 & 505,000 & 1,000 & 4005,000 & 715,500 & 466,800 & 48,000 & 5800,000 \\
Escolaridade & 0,820 & 0,213 & 0,000 & 1,000 & 0,780 & 0,244 & 0,000 & 1,000 \\
Infraestrutura & 0,840 & 0,114 & 0,260 & 1,000 & 0,820 & 0,124 & 0,020 & 1,000 \\
Experiência & 0,620 & 0,270 & 0,000 & 1,000 & 0,640 & 0,287 & 0,000 & 1,000 \\
Matemática & 195,200 & 21,250 & 88,310 & 331,900 & 203,900 & 25,100 & 116,400 & 319,300 \\
Português & 178,500 & 18,930 & 95,320 & 283,800 & 184,200 & 21,270 & 90,000 & 298,400 \\
Aprovação & 0,690 & 0,190 & 0,000 & 1,000 & 0,680 & 0,171 & 0,000 & 1,000 \\
\hline & & & & & 2013 & \\
\hline Variáveis & Média & Desvio Padrão & Mínimo & Máximo & Média & Desvio Padrão & Mínimo & Máximo \\
\hline Salas de aula & 11,110 & 5,792 & 2,000 & 71,000 & 10,290 & 5,772 & 3,000 & 116,000 \\
Funcionários & 53,920 & 30,740 & 2,000 & 154,000 & 49,030 & 31,430 & 2,000 & 213,000 \\
Matrículas & 703,000 & 474,000 & 39,000 & 5164,000 & 598,400 & 405,800 & 22,000 & 4634,000 \\
Escolaridade & 0,780 & 0,248 & 0,000 & 1,000 & 0,780 & 0,245 & 0,000 & 1,000 \\
Infraestrutura & 0,800 & 0,128 & 0,100 & 1,000 & 0,750 & 0,157 & 0,000 & 1,000 \\
Experiência & 0,620 & 0,241 & 0,000 & 1,000 & 0,710 & 0,362 & 0,000 & 1,000 \\
Matemática & 208,700 & 24,820 & 122,700 & 302,200 & 206,700 & 28,700 & 88,930 & 320,000 \\
Português & 190,900 & 21,100 & 104,000 & 273,700 & 191,800 & 25,910 & 86,270 & 315,700 \\
Aprovação & 0,700 & 0,174 & 0,000 & 1,000 & 0,690 & 0,197 & 0,000 & 1,000 \\
\hline Nota: As estatísticas foram corrigidas pelos pesos amostrais. & & & &
\end{tabular}

Nota: As estatísticas foram corrigidas pelos pesos amostrais.

Fonte: Elaborado pelos autores com base nos microdados da Prova Brasil e do Censo Escolar/INEP. 


\begin{tabular}{|c|c|c|c|c|c|c|c|c|}
\hline \multirow[b]{2}{*}{ Variáveis } & \multicolumn{4}{|c|}{2007} & \multicolumn{4}{|c|}{2009} \\
\hline & Média & Desvio Padrão & Mínimo & Máximo & Média & Desvio Padrão & Mínimo & Máximo \\
\hline Salas de aula & 13,320 & 5,772 & 1,000 & 72,000 & 12,450 & 5,855 & 1,000 & 114,000 \\
\hline Funcionários & 66,310 & 30,430 & 4,000 & 181,000 & 62,530 & 31,630 & 7,000 & 193,000 \\
\hline Matrículas & 983,500 & 537,300 & 1,000 & 4064,000 & 883,200 & 520,500 & 53,000 & 5800,000 \\
\hline Escolaridade & 0,890 & 0,167 & 0,000 & 1,000 & 0,850 & 0,209 & 0,000 & 1,000 \\
\hline Infraestrutura & 0,873 & 0,109 & 0,160 & 1,000 & 0,850 & 0,121 & 0,080 & 1,000 \\
\hline Experiência & 0,656 & 0,368 & 0,000 & 1,000 & 0,605 & 0,436 & 0,000 & 1,000 \\
\hline Matemática & 240,100 & 19,510 & 62,490 & 350,500 & 240,200 & 20,700 & 161,900 & 356,400 \\
\hline Português & 229,200 & 17,230 & 157,800 & 311,700 & 237,700 & 19,430 & 133,400 & 314,700 \\
\hline \multirow[t]{2}{*}{ Aprovação } & 0,646 & 0,165 & 0,000 & 1,000 & 0,628 & 0,154 & 0,000 & 1,000 \\
\hline & \multicolumn{4}{|c|}{2011} & \multicolumn{4}{|c|}{2013} \\
\hline Variáveis & Média & Desvio Padrão & Mínimo & Máximo & Média & Desvio Padrão & Mínimo & Máximo \\
\hline Salas de aula & 12,640 & 5,794 & 2,000 & 71,000 & 11,460 & 5,360 & 2,000 & 61,000 \\
\hline Funcionários & 66,710 & 32,940 & 6,000 & 195,000 & 62,770 & 31,240 & 3,000 & 268,000 \\
\hline Matrículas & 930,200 & 550,900 & 62,000 & 5153,000 & 934,500 & 621,200 & 38,000 & 4634,000 \\
\hline Escolaridade & 0,882 & 0,173 & 0,000 & 1,000 & 0,857 & 0,180 & 0,000 & 1,000 \\
\hline Infraestrutura & 0,840 & 0,122 & 0,000 & 1,000 & 0,721 & 0,163 & 0,040 & 1,000 \\
\hline Experiência & 0,633 & 0,369 & 0,000 & 1,000 & 0,882 & 0,382 & 0,000 & 1,000 \\
\hline Matemática & 244,200 & 21,630 & 166,300 & 345,900 & 233,100 & 18,350 & 157,600 & 321,300 \\
\hline Português & 238,500 & 19,680 & 155,200 & 316,600 & 232,200 & 19,280 & 137,600 & 304,700 \\
\hline Aprovação & 0,637 & 0,156 & 0,000 & 1,000 & 0,596 & 0,181 & 0,000 & 1,000 \\
\hline
\end{tabular}

Nota: As estatísticas foram corrigidas pelos pesos amostrais.

Fonte: Elaborado pelos autores com base nos microdados da Prova Brasil e do Censo Escolar/INEP. 
Tabela 7: Correlação entre insumos e produtos

\begin{tabular}{|c|c|c|c|c|c|c|c|c|c|}
\hline & \multicolumn{9}{|c|}{$4^{\mathrm{a}}$ série } \\
\hline & Salas de Aula & Funcionários & Matrículas & Escolaridade & Infraestrutura & Experiência & Matemática & Português & Aprovação \\
\hline Salas de aula & 1 & & & & & & & & \\
\hline Funcionários & $0,700^{* * *}$ & 1 & & & & & & & \\
\hline Matrículas & $0,645^{* * *}$ & $0,754^{* * *}$ & 1 & & & & & & \\
\hline Escolaridade & $0,277^{* * *}$ & $0,238^{* * *}$ & $0,207^{* * *}$ & 1 & & & & & \\
\hline Infraestrutura & $0,455^{* * *}$ & $0,400^{* * *}$ & $0,339^{* * * *}$ & $0,380^{* * * *}$ & 1 & & & & \\
\hline Experiência & $0,115^{* * *}$ & $0,077^{* * * *}$ & $0,138^{* * * *}$ & $0,119^{* * * *}$ & $0,205^{* * * *}$ & 1 & & & \\
\hline Matemática & $0,179^{* * * *}$ & $0,092^{* * *}$ & $0,013^{* * *}$ & $0,326^{* * * *}$ & $0,368^{* * * *}$ & $0,011^{* * *}$ & 1 & & \\
\hline Português & $0,175^{* * *}$ & $0,102^{* * * *}$ & $0,025^{* * *}$ & $0,326^{* * *}$ & $0,352^{* * * *}$ & $-0,008$ & $0,918^{* * *}$ & 1 & \\
\hline \multirow[t]{2}{*}{ Aprovação } & $0,136^{* * *}$ & $0,077^{* * * *}$ & $0,070^{* * *}$ & $0,258^{* * * *}$ & $0,271^{* * * *}$ & $0,082^{* * * *}$ & $0,499^{* * * *}$ & $0,519^{* * * *}$ & 1 \\
\hline & \multicolumn{9}{|c|}{$8^{a}$ série } \\
\hline Salas de aula & 1 & & & & & & & & \\
\hline Funcionários & $0,684^{* * *}$ & 1 & & & & & & & \\
\hline Matrículas & $0,611^{* * *}$ & $0,737^{* * *}$ & 1 & & & & & & \\
\hline Escolaridade & $0,197^{* * *}$ & $0,197^{* * *}$ & $0,189^{* * *}$ & 1 & & & & & \\
\hline Infraestrutura & $0,379^{* * *}$ & $0,359^{* * *}$ & $0,289^{* * *}$ & $0,339^{* * *}$ & 1 & & & & \\
\hline Experiência & $0,088^{* * *}$ & $0,066^{* * *}$ & $0,098^{* * *}$ & $0,150^{* * *}$ & $0,209^{* * *}$ & 1 & & & \\
\hline Matemática & $0,183^{* * *}$ & $0,129^{* * *}$ & $0,026^{* * *}$ & $0,295^{* * *}$ & $0,314^{* * * *}$ & $0,083^{* * *}$ & 1 & & \\
\hline Português & $0,182^{* * *}$ & $0,153^{* * *}$ & $0,071^{* * *}$ & $0,293^{* * *}$ & $0,288^{* * *}$ & $-0,025$ & $0,861^{* * *}$ & 1 & \\
\hline Aprovação & $0,106^{* * *}$ & $0,084^{* * *}$ & $0,084^{* * *}$ & $0,218^{* * *}$ & $0,189^{* * *}$ & $0,129^{* * *}$ & $0,368^{* * *}$ & $0,362^{* * *}$ & 1 \\
\hline
\end{tabular}

Fonte: Elaborado pelos autores com base nos microdados da Prova Brasil e do Censo Escolar/INEP 
Tabela 8: Estatísticas descritivas das variáveis não discricionárias - $4^{a}$ série

\begin{tabular}{|c|c|c|c|c|c|c|c|c|}
\hline \multirow[b]{2}{*}{ Variáveis } & \multicolumn{4}{|c|}{2007} & \multicolumn{4}{|c|}{2009} \\
\hline & Média & Desvio Padrão & Mínimo & Máximo & Média & Desvio Padrão & Mínimo & Máximo \\
\hline Homem & 0,4800 & 0,1290 & 0,0000 & 1,0000 & 0,5000 & 0,1010 & 0,0000 & 1,0000 \\
\hline Branco & 0,3400 & 0,1880 & 0,0000 & 1,0000 & 0,3100 & 0,1590 & 0,0000 & 1,0000 \\
\hline Idade & 10,7700 & 0,5760 & 8,0000 & 15,0000 & 10,8800 & 0,5280 & 9,4200 & 14,4000 \\
\hline Mãe & 0,9000 & 0,0920 & 0,0000 & 1,0000 & 0,9000 & 0,0670 & 0,3300 & 1,0000 \\
\hline Mãe com superior & 0,3200 & 0,1280 & 0,0000 & 1,0000 & 0,3000 & 0,1190 & 0,0000 & 1,0000 \\
\hline Socioeconômico & 0,4200 & 0,0760 & 0,1400 & 0,8700 & 0,3300 & 0,0770 & 0,0200 & 0,7200 \\
\hline Incentivo escolar & 0,9500 & 0,0380 & 0,4000 & 1,0000 & 0,9400 & 0,0360 & 0,6200 & 1,0000 \\
\hline \multirow[t]{2}{*}{ Creche } & 0,3700 & 0,1970 & 0,0000 & 1,0000 & 0,3800 & 0,1820 & 0,0000 & 1,0000 \\
\hline & \multicolumn{4}{|c|}{2011} & \multicolumn{4}{|c|}{2013} \\
\hline Variáveis & Média & Desvio Padrão & Mínimo & Máximo & Média & Desvio Padrão & Mínimo & Máximo \\
\hline Homem & 0,4800 & 0,1000 & 0,0000 & 1,0000 & 0,4800 & 0,1370 & 0,0000 & 1,0000 \\
\hline Branco & 0,2600 & 0,1400 & 0,0000 & 1,0000 & 0,2500 & 0,1630 & 0,0000 & 1,0000 \\
\hline Idade & 10,8700 & 0,5100 & 9,5000 & 13,6900 & 11,0000 & 0,5550 & 8,0000 & 15,0000 \\
\hline Mãe & 0,9100 & 0,0630 & 0,2900 & 1,0000 & 0,8900 & 0,0940 & 0,0000 & 1,0000 \\
\hline Mãe com superior & 0,1009 & 0,0770 & 0,0000 & 0,6900 & 0,1000 & 0,0910 & 0,0000 & 1,0000 \\
\hline Socioeconômico & 0,4500 & 0,0780 & 0,1000 & 0,6900 & 0,4700 & 0,0900 & 0,0000 & 1,0000 \\
\hline Incentivo escolar & 0,9400 & 0,0380 & 0,2700 & 1,0000 & 0,9400 & 0,0500 & 0,0000 & 1,0000 \\
\hline Creche & 0,3900 & 0,1660 & 0,0000 & 1,0000 & 0,4000 & 0,1900 & 0,0000 & 1,0000 \\
\hline
\end{tabular}

Nota: As estatísticas foram corrigidas pelos pesos amostrais.

Fonte: Elaborado pelos autores com base nos microdados da Prova Brasil e do Censo Escolar/INEP. 
Tabela 9: Estatísticas descritivas das variáveis não discricionárias - $8^{\mathrm{a}}$ série

\begin{tabular}{|c|c|c|c|c|c|c|c|c|}
\hline \multirow[b]{2}{*}{ Variáveis } & \multicolumn{4}{|c|}{2007} & \multicolumn{4}{|c|}{2009} \\
\hline & Média & Desvio Padrão & Mínimo & Máximo & Média & Desvio Padrão & Mínimo & Máximo \\
\hline Homem & 0,440 & 0,100 & 0,000 & 1,000 & 0,440 & 0,105 & 0,000 & 1,000 \\
\hline Branco & 0,340 & 0,192 & 0,000 & 1,000 & 0,300 & 0,183 & 0,000 & 1,000 \\
\hline Idade & 15,020 & 0,641 & 13,040 & 19,630 & 13,500 & 0,469 & 13,000 & 18,240 \\
\hline Mãe & 0,880 & 0,081 & 0,000 & 1,000 & 0,880 & 0,073 & 0,000 & 1,000 \\
\hline Mãe com superior & 0,150 & 0,073 & 0,000 & 0,780 & 0,150 & 0,079 & 0,000 & 1,000 \\
\hline Socioeconômico & 0,360 & 0,072 & 0,160 & 0,620 & 0,340 & 0,080 & 0,090 & 0,840 \\
\hline Incentivo escolar & 0,930 & 0,031 & 0,660 & 1,000 & 0,930 & 0,032 & 0,350 & 1,000 \\
\hline \multirow[t]{2}{*}{ Creche } & 0,450 & 0,224 & 0,000 & 1,000 & 0,440 & 0,211 & 0,000 & 1,000 \\
\hline & \multicolumn{4}{|c|}{2011} & \multicolumn{4}{|c|}{2013} \\
\hline Variáveis & Média & Desvio Padrão & Mínimo & Máximo & Média & Desvio Padrão & Mínimo & Máximo \\
\hline Homem & 0,450 & 0,094 & 0,000 & 1,000 & 0,460 & 0,139 & 0,000 & 1,000 \\
\hline Branco & 0,250 & 0,147 & 0,000 & 0,870 & 0,150 & 0,093 & 0,000 & 1,000 \\
\hline Idade & 15,930 & 0,471 & 14,450 & 19,800 & 16,090 & 0,625 & 13,000 & 20,000 \\
\hline Mãe & 0,890 & 0,064 & 0,000 & 1,000 & 0,840 & 0,104 & 0,000 & 1,000 \\
\hline Mãe com superior & 0,070 & 0,068 & 0,000 & 0,860 & 0,100 & 0,104 & 0,000 & 1,000 \\
\hline Socioeconômico & 0,470 & 0,077 & 0,160 & 0,700 & 0,450 & 0,082 & 0,060 & 0,760 \\
\hline Incentivo escolar & 0,930 & 0,028 & 0,680 & 1,000 & 0,930 & 0,039 & 0,440 & 1,000 \\
\hline Creche & 0,350 & 0,164 & 0,000 & 1,000 & 0,330 & 0,187 & 0,000 & 1,000 \\
\hline
\end{tabular}

Nota: As estatísticas foram corrigidas pelos pesos amostrais.

Fonte: Elaborado pelos autores com base nos microdados da Prova Brasil e do Censo Escolar/INEP. 
Tabela 10: Estatísticas descritivas dos determinantes da eficiência gerencial - $4^{a}$ série

\begin{tabular}{|c|c|c|c|c|c|c|c|c|}
\hline \multirow[b]{2}{*}{ Variáveis } & \multicolumn{4}{|c|}{2007} & \multicolumn{4}{|c|}{2009} \\
\hline & Média & Desvio Padrão & Mínimo & Máximo & Média & Desvio Padrão & Mínimo & Máximo \\
\hline Diretoria & 0,630 & 0,483 & 0,000 & 1,000 & 0,560 & 0,496 & 0,000 & 1,000 \\
\hline Conselho & 0,680 & 0,467 & 0,000 & 1,000 & 0,660 & 0,473 & 0,000 & 1,000 \\
\hline Projeto & 0,070 & 0,259 & 0,000 & 1,000 & 0,070 & 0,249 & 0,000 & 1,000 \\
\hline Admissão & 0,280 & 0,447 & 0,000 & 1,000 & 0,260 & 0,439 & 0,000 & 1,000 \\
\hline Interferência & 0,380 & 0,486 & 0,000 & 1,000 & 0,400 & 0,490 & 0,000 & 1,000 \\
\hline Livro & 0,770 & 0,422 & 0,000 & 1,000 & 0,710 & 0,454 & 0,000 & 1,000 \\
\hline Apoio & 0,960 & 0,204 & 0,000 & 1,000 & 0,950 & 0,209 & 0,000 & 1,000 \\
\hline Homogeneidade idade & 0,400 & 0,490 & 0,000 & 1,000 & 0,410 & 0,491 & 0,000 & 1,000 \\
\hline Homogeneidade rendimento & 0,070 & 0,257 & 0,000 & 1,000 & 0,070 & 0,253 & 0,000 & 1,000 \\
\hline Heterogeneidade idade & 0,080 & 0,273 & 0,000 & 1,000 & 0,090 & 0,289 & 0,000 & 1,000 \\
\hline \multirow[t]{2}{*}{ Heterogeneidade rendimento } & 0,240 & 0,428 & 0,000 & 1,000 & 0,220 & 0,413 & 0,000 & 1,000 \\
\hline & \multicolumn{4}{|c|}{2011} & \multicolumn{4}{|c|}{2013} \\
\hline Variáveis & Média & Desvio Padrão & Mínimo & Máximo & Média & Desvio Padrão & Mínimo & Máximo \\
\hline Diretoria & 0,500 & 0,500 & 0,000 & 1,000 & 0,200 & 0,401 & 0,000 & 1,000 \\
\hline Conselho & 0,620 & 0,485 & 0,000 & 1,000 & 0,670 & 0,254 & 0,000 & 1,000 \\
\hline Projeto & 0,010 & 0,108 & 0,000 & 1,000 & 0,040 & 0,491 & 0,000 & 1,000 \\
\hline Admissão & 0,100 & 0,302 & 0,000 & 1,000 & 0,370 & 0,484 & 0,000 & 1,000 \\
\hline Interferência & 0,390 & 0,487 & 0,000 & 1,000 & 0,360 & 0,481 & 0,000 & 1,000 \\
\hline Livro & 0,710 & 0,453 & 0,000 & 1,000 & 0,730 & 0,173 & 0,000 & 1,000 \\
\hline Apoio & 0,960 & 0,194 & 0,000 & 1,000 & 0,950 & 0,228 & 0,000 & 1,000 \\
\hline Homogeneidade idade & 0,020 & 0,142 & 0,000 & 1,000 & 0,430 & 0,494 & 0,000 & 1,000 \\
\hline Homogeneidade rendimento & 0,010 & 0,092 & 0,000 & 1,000 & 0,080 & 0,264 & 0,000 & 1,000 \\
\hline Heterogeneidade idade & 0,450 & 0,497 & 0,000 & 1,000 & 0,090 & 0,288 & 0,000 & 1,000 \\
\hline Heterogeneidade rendimento & 0,350 & 0,478 & 0,000 & 1,000 & 0,170 & 0,376 & 0,000 & 1,000 \\
\hline
\end{tabular}

Fonte: Elaborado pelos autores com base nos microdados da Prova Brasil e do Censo Escolar/INEP. 
Tabela 11: Estatísticas descritivas dos determinantes da eficiência gerencial - $8^{a}$ série

\begin{tabular}{|c|c|c|c|c|c|c|c|c|}
\hline \multirow[b]{2}{*}{ Variáveis } & \multicolumn{4}{|c|}{2007} & \multicolumn{4}{|c|}{2009} \\
\hline & Média & Desvio Padrão & Mínimo & Máximo & Média & Desvio Padrão & Mínimo & Máximo \\
\hline Diretoria & 0,680 & 0,468 & 0,000 & 1,000 & 0,620 & 0,486 & 0,000 & 1,000 \\
\hline Conselho & 0,690 & 0,462 & 0,000 & 1,000 & 0,680 & 0,468 & 0,000 & 1,000 \\
\hline Projeto & 0,080 & 0,264 & 0,000 & 1,000 & 0,070 & 0,251 & 0,000 & 1,000 \\
\hline Admissão & 0,250 & 0,431 & 0,000 & 1,000 & 0,240 & 0,425 & 0,000 & 1,000 \\
\hline Interferência & 0,350 & 0,476 & 0,000 & 1,000 & 0,380 & 0,485 & 0,000 & 1,000 \\
\hline Livro & 0,850 & 0,354 & 0,000 & 1,000 & 0,790 & 0,407 & 0,000 & 1,000 \\
\hline Apoio & 0,950 & 0,222 & 0,000 & 1,000 & 0,940 & 0,234 & 0,000 & 1,000 \\
\hline Homogeneidade idade & 0,430 & 0,496 & 0,000 & 1,000 & 0,430 & 0,495 & 0,000 & 1,000 \\
\hline Homogeneidade rendimento & 0,050 & 0,222 & 0,000 & 1,000 & 0,050 & 0,216 & 0,000 & 1,000 \\
\hline Heterogeneidade idade & 0,090 & 0,283 & 0,000 & 1,000 & 0,100 & 0,297 & 0,000 & 1,000 \\
\hline \multirow[t]{2}{*}{ Heterogeneidade rendimento } & 0,220 & 0,414 & 0,000 & 1,000 & 0,190 & 0,395 & 0,000 & 1,000 \\
\hline & \multicolumn{4}{|c|}{2011} & \multicolumn{4}{|c|}{2013} \\
\hline Variáveis & Média & Desvio Padrão & Mínimo & Máximo & Média & Desvio Padrão & Mínimo & Máximo \\
\hline Diretoria & 0,430 & 0,495 & 0,000 & 1,000 & 0,210 & 0,405 & 0,000 & 1,000 \\
\hline Conselho & 0,670 & 0,471 & 0,000 & 1,000 & 0,690 & 0,279 & 0,000 & 1,000 \\
\hline Projeto & 0,010 & 0,113 & 0,000 & 1,000 & 0,080 & 0,485 & 0,000 & 1,000 \\
\hline Admissão & 0,110 & 0,314 & 0,000 & 1,000 & 0,230 & 0,422 & 0,000 & 1,000 \\
\hline Interferência & 0,370 & 0,484 & 0,000 & 1,000 & 0,360 & 0,480 & 0,000 & 1,000 \\
\hline Livro & 0,820 & 0,381 & 0,000 & 1,000 & 0,720 & 0,155 & 0,000 & 1,000 \\
\hline Apoio & 0,950 & 0,216 & 0,000 & 1,000 & 0,920 & 0,278 & 0,000 & 1,000 \\
\hline Homogeneidade idade & 0,020 & 0,143 & 0,000 & 1,000 & 0,550 & 0,497 & 0,000 & 1,000 \\
\hline Homogeneidade rendimento & 0,010 & 0,092 & 0,000 & 1,000 & 0,050 & 0,219 & 0,000 & 1,000 \\
\hline Heterogeneidade idade & 0,410 & 0,492 & 0,000 & 1,000 & 0,110 & 0,312 & 0,000 & 1,000 \\
\hline Heterogeneidade rendimento & 0,370 & 0,483 & 0,000 & 1,000 & 0,070 & 0,255 & 0,000 & 1,000 \\
\hline
\end{tabular}

Fonte: Elaborado pelos autores com base nos microdados da Prova Brasil e do Censo Escolar/INEP. 
processo seletivo. As estimativas mostram que a porcentagem de diretores que atuam em seus cargos em decorrência de seleção se reduziu de $63 \%$ para $20 \%$ para a $4^{\text {a }}$ série; e de $68 \%$ para $21 \%$ no caso da $8^{\text {a }}$ série. Com relação ao conselho escolar nota-se que não houve piora desse indicador. Em torno de $65,25 \%$ e $68,25 \%$ das unidades de ensino reuniram seus conselhos escolares três vezes ou mais no ano e houve estabilização desse indicador no período de análise. A eles cabe deliberar sobre as normas internas e o funcionamento da escola, além de participar da elaboração do projeto pedagógico. Também tem a função de: analisar as questões encaminhadas pelos diversos segmentos da escola, propondo sugestões; acompanhar a execução das ações pedagógicas, administrativas e financeiras da escola e mobilizar a comunidade escolar e local para a participação em atividades em prol da melhoria da qualidade da educação, como previsto em lei ${ }^{13}$.

O projeto pedagógico da escola traduz a proposta educativa construída pela comunidade escolar no exercício de sua autonomia, com base nas características dos alunos, nos profissionais e recursos disponíveis, tendo como referência as orientações curriculares nacionais e dos respectivos sistemas de ensino. Assim, ao assegurar a ampla participação dos profissionais da escola, da família e dos alunos na definição das orientações e dos processo de implantação dos mesmos há a construção de uma "sociedade" escolar mais igualitária e participativa, melhorando os resultados acadêmicos dos alunos. Conforme as estatísticas apontadas aqui, a porcentagem de escolas em que pais, professores, diretor, alunos e outros servidores se reuniram para elaborar o projeto pedagógico caiu de $7 \%$ para $4 \%$ para as escolas da $4^{\text {a }}$ série; para a $8^{\text {a }}$ série, o valor permaneceu em $8 \%$ entre 2007 e 2013, porém apresentou uma queda abrupta em 2011 (alcançando 1\%) com recuperação na avaliação seguinte. Esses resultados demonstram o baixo envolvimento dos diversos atores educacionais no processo de definição das regras que irão orientar a trajetória de aprendizagem dos alunos.

Os diretores também relataram mudanças nas interferências em suas gestões. Para a $4^{\text {a }}$ série houve redução muito pequena nessas ocorrências e aumento ínfimo para a $8^{a}$ série. Todavia, é interessante observar que mais de $35 \%$ dos diretores notificaram que agentes externos tentaram interferir em suas práticas de gestão. Essas tentativas podem prejudicar as técnicas de administração propostas pelo diretor, uma vez que o mesmo conhece a comunidade e o ambiente escolar e suas principais demandas. Ao mesmo tempo, observam-se altos índices de apoio da comunidade escolar quanto às práticas de gerência por parte do diretor - acima de $90 \%$ nos quatro anos analisados.

Outra medida de autonomia escolar é a escolha do livro didático. É uma tarefa que cabe aos professores e a equipe pedagógica e tem por objetivo analisar as resenhas contidas no guia para escolher adequadamente os livros a serem utilizados no triênio. O livro didático deve ser adequado ao projeto pedagógico da escola; ao aluno e professor; e à realidade sociocultural das instituições. Entre 2007 e 2013, houve uma redução de 77\% para 73\% das escolas ( $4^{\text {a }}$ série) que escolheram seus livros didáticos; para a $8^{a}$ série, essa redução chega a 13 pontos percentuais.

Por fim, considerou-se o critério de alocação dos alunos entre as turmas como última medida de autonomia escolar. Para ambas as séries do ensino fundamental, o principal parâmetro estabelecido pelo diretor para formar as

${ }^{13}$ Para mais detalhes, ver o Programa Nacional de Fortalecimento dos Conselhos Escolares. 
turmas foi o de homogeneidade quanto à idade, com mais de $40 \%$ das escolas adotando esse método. Esse critério respalda-se na regra do Ministério da Educação ${ }^{14}$, a qual define que, para ingressar no $1^{\circ}$ ano do ensino fundamental, as crianças precisam ter no mínimo seis anos de idade completos até março. Espera-se minimizar as diferenças de idade entre os alunos e, indiretamente, obter menores taxas de defasagem idade-série. A literatura sobre peer effects indica que esse tipo de critério de organização de turmas ainda é pouco explorado, mas parece ter impactos positivos sobre as habilidades cognitivas dos alunos (Ordine et al. 2015).

A partir do exposto anteriormente, procede-se à análise dos resultados obtidos para as medidas de eficiência escolar, a relação com as variáveis nãodiscricionárias e a associação existente entre autonomia na gestão da escola e a eficiência do diretor na combinação entre insumos e produtos.

\section{Resultados Econométricos}

\subsection{Escores de Eficiência Técnica}

Para avaliar como a distribuição empírica da eficiência ${ }^{15}$ das escolas variou entre 2007 e 2013, apresenta-se a função densidade de probabilidade para as eficiências técnica (sem desconto das variáveis não-discricionárias) e gerencial para as duas séries do ensino fundamental, conforme as Figuras 1 e 2.

Ao comparar as curvas estimadas na Figura 1, o primeiro aspecto observado é o deslocamento muito modesto para a esquerda da curva de densidade de probabilidade para a medida de eficiência técnica, sendo que essa mudança não é tão pronunciada para os resultados da $4^{\text {a }}$ série. Também se nota que há uma maior concentração, ao longo do período analisado, de escolas em torno da média, como pode ser observado pelo aplainamento das caudas das densidades estimadas. Quando se retira o efeito das variáveis não discricionárias, isto é, aqueles elementos de origem do aluno e de sua família, observa-se que as densidades estimadas tornam-se "ligeiramente" assimétricas e colapsam, de tal forma que houve poucas mudanças efetivas na densidade da eficiência gerencial - Figura 2. Essas evidências demonstram, em parte, que a gerência dos recursos educacionais que estão sob o controle dos gestores locais não apresentou melhorias efetivas no período de análise. Além disso, percebe-se que o background familiar ainda é um componente importante para explicar os resultados educacionais brasileiros.

Para verificar se houve alterações na capacidade do administrador escolar em promover um balanceamento adequado entre insumos e produtos no período 2007-2013 se realizaram dois testes não paramétricos: o teste de Kolmogorov-Smirnov (K-S) e o teste de Epps-Singleton (E-S). Os resultados dos testes de igualdade de distribuições estão apresentados na Tabela 12 e indicaram que as distribuições de probabilidade são diferentes entre si e estatisticamente significativas. Isso é uma evidência modesta de que as práticas

\footnotetext{
${ }^{14}$ Segue a resolução do Conselho Nacional de Educação/CEB 6/2010, Art. $3^{\circ}$.

${ }^{15}$ Foi computada considerano-se os seguintes insumos: o número de salas de aula, o total de funcionários, o total de alunos da escola, o percentual de professores com ensino superior, um indicador de experiência do diretor e uma medida de infraestrutura escolar. Para os produtos, foram considerados as notas médias nas provas de Matemática e Português e a taxa média de aprovação.
} 
Figura 1: Densidade estimada da eficiência técnica
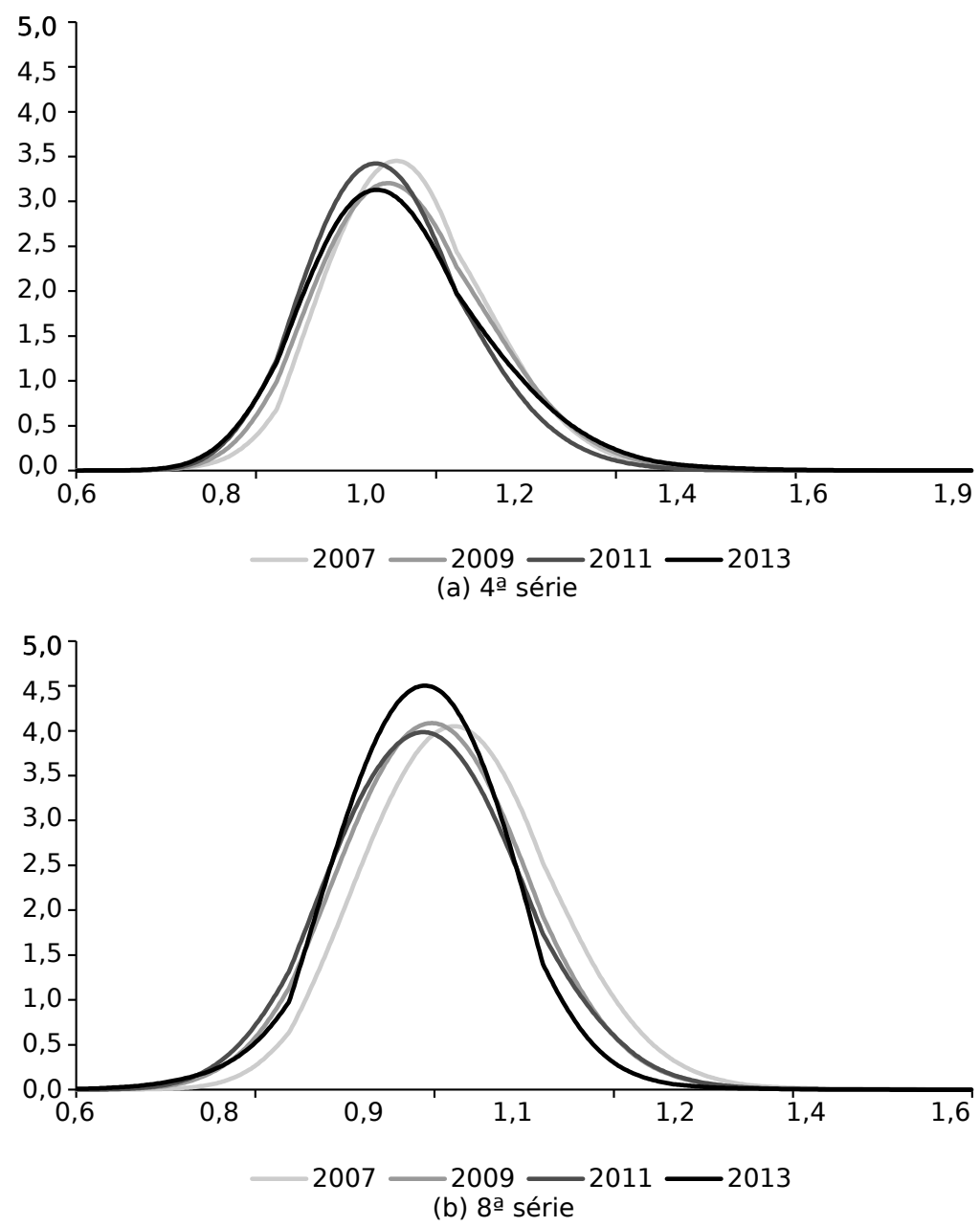

Fonte: Elaborado pelos autores.

Tabela 12: Teste de igualdade de distribuições

\begin{tabular}{|c|c|c|c|c|}
\hline & \multicolumn{4}{|c|}{$4^{\mathrm{a}}$ série } \\
\hline & \multicolumn{2}{|c|}{ Eficiência Técnica } & \multicolumn{2}{|c|}{ Eficiência Gerencial } \\
\hline & Estatística & p-value & Estatística & p-value \\
\hline Kolmogorov-Smirnov & 0,1200 & 0,0000 & 0,0780 & 0,0000 \\
\hline \multirow[t]{2}{*}{ Epps-Singleton } & 441,9070 & 0,0000 & 216,0230 & 0,0000 \\
\hline & \multicolumn{4}{|c|}{$8^{a}$ série } \\
\hline Kolmogorov-Smirnov & 0,2480 & 0,0000 & 0,0330 & 0,0740 \\
\hline Epps-Singleton & 1171,9020 & 0,0000 & 12,0650 & 0,0170 \\
\hline
\end{tabular}

Os valores críticos para a estatística de teste de Kolmogorov-Smirnov são $\frac{1,22}{\sqrt{n}}, \frac{1,36}{\sqrt{n}}$ e $\frac{1,63}{\sqrt{n}}$ para os níveis de significância de $10 \%, 5 \%$ e $1 \%$, respectivamente; para o teste de Epps-Singleton são 7,779, 9,488 e $13,277$.

Fonte: Elaborado pelos autores com base nos microdados da Prova Brasil e do Censo Escolar/INEP. 
Figura 2: Densidade estimada da eficiência gerencial

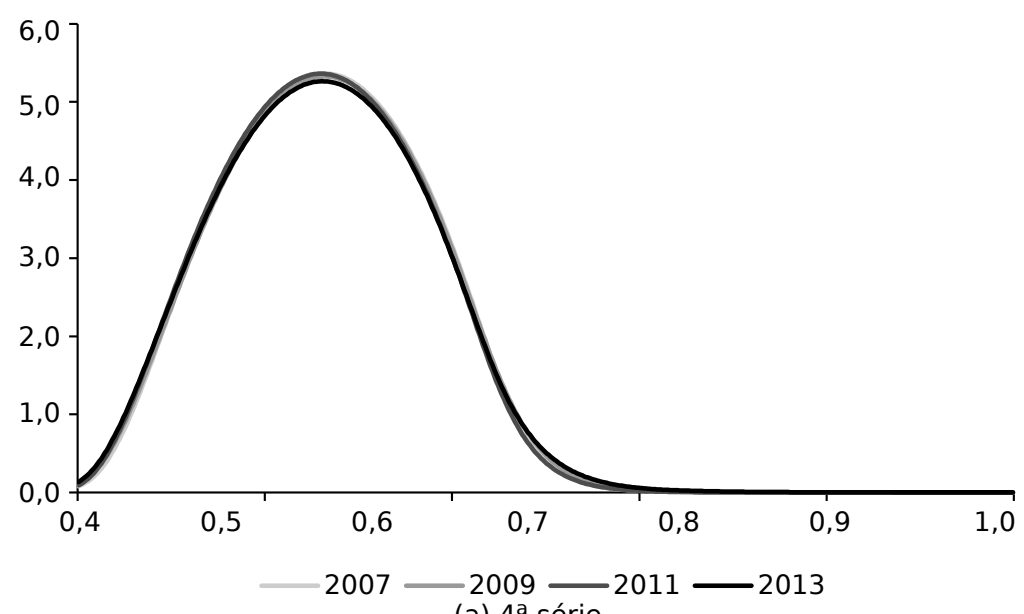

(a) 4a série

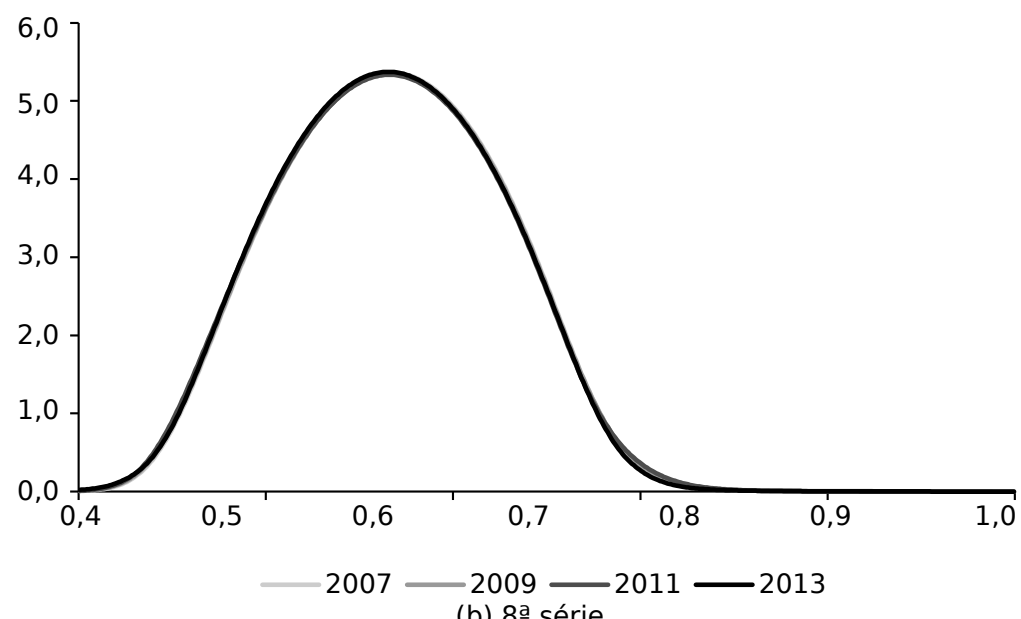

Fonte: Elaborado pelos autores.

de gestão foram distintas entre os anos, porém as mesmas não possibilitaram mudanças consideráveis no ambiente escolar.

Finalmente, as Tabelas 13 a 14 apresentam estatísticas descritivas acerca das medidas de eficiência técnica e gerencial por região geográfica e série do ensino fundamental. O primeiro comportamento observado, e já mencionado anteriormente, é a redução gradativa de ambas as medidas de eficiência. Isso indica que as práticas de gestão adotadas pelos administradores escolares não tiveram por primazia o melhor balanceamento entre insumos e produtos, isto é, os gestores podem ter outros objetivos que não a alocação ótima de insumos, que resultaria na maximização dos produtos educacionais.

Em segundo lugar, nota-se que a eficiência técnica média é maior para os estados pertencentes às regiões Nordeste e Norte. Após a retirada dos efeitos não discricionários, as regiões Nordeste e Sul passaram a figurar entre aquelas com melhores práticas de gestão. Como a medida de eficiência reflete a interação entre insumos e produtos, unidades geográficas com piores desempenhos nos testes padronizados e altas taxas de reprovação, por exemplo, 
podem apresentar melhor gestão do que outras se utilizarem seus recursos disponíveis de forma mais eficientes do que aquelas. Nesse sentido, o ideal não necessariamente é aumentar os recursos disponíveis, mas sim utilizá-los de forma melhor.

Quando se comparam os resultados das duas medidas de eficiência, verifica-se que há uma diferença substancial entre os escores. Para a $4^{a}$ série do ensino fundamental, as eficiências técnica e gerencial são, na média, de 1,05 e de 0,60 , respectivamente. Para a $8^{a}$ série, os valores correspondentes são 1,02 e 0,68 . Isso significa que o ambiente sociocultural e o capital econômico da família dos alunos são responsáveis por quase um terço do diferencial entre os escores. Para caracterizar o background socioeconômico familiar, seguiu-se a abordagem de (Soares \& Collares 2006, p. 617), que consiste em um "conceito multidimensional". Assim, consideraram-se três dimensões que descreveriam a condição familiar: recursos econômicos, relação dos pais com a educação dos filhos e presença da mãe na família.

Ainda nessa linha, espera-se que os alunos com melhores condições em seus ambientes familiares se apropriem mais rapidamente das melhorias da escola. Disso decorre que seria a piora e a baixa mobilidade do background familiar que poderia atuar como limitante da capacidade do gestor escolar em promover ganhos para toda a comunidade escolar. Como verificado anteriormente, houve piora em algumas instâncias que compõem o capital familiar do aluno e manutenção em outras. Isso permite explicar os diferenciais observados nos escores de eficiência.

Esses resultados mostram que apresentar bons indicadores educacionais em testes padronizados não necessariamente significa que aquela região terá uma eficiência relativa maior que outras que não possuam os mesmos índices. Isso porque os recursos destinados para alcançar tais resultados podem ser muito superiores proporcionalmente aos demais entes da federação, dentre eles, melhores infraestrutura escolar e qualificação dos professores, por exemplo. Com isso, regiões desenvolvidas aparecem em posições inferiores a outras que historicamente sofreram com um maior nível de vulnerabilidades sociais e um nível precário de investimentos públicos, o que à primeira vista pode parecer um resultado paradoxal.

Apesar de algumas regiões com histórico de bom desempenho em testes de aprendizagem apresentarem níveis de eficiência abaixo de regiões historicamente marcadas por resultados educacionais inferiores, é importante ressaltar que nem sempre um fato está diretamente correlacionado ao outro. Seria possível que escolas de algumas regiões com altos níveis de desempenho escolar alcançassem o mesmo resultado com a injeção de menos recursos, o que coloca aquela região no rol de unidades menos eficientes. Desse modo, o balanceamento adequado entre insumos e produtos conduz, como resultado final, à melhoria da eficiência escolar, por meio de uma cadeia de causas que difere em particularidades, mas que envolve, em geral, realocação e melhor uso dos insumos produtivos, caracterizando, assim, um processo dinâmico que apresenta path dependence.

A despeito da posição relativa que cada região ocupa no ranking de eficiência no período analisado, é importante salientar que houve uma piora no escore para todas as unidades geográficas de análise, revelando uma deterioração nas formas de aplicação gerencial dos recursos, devido às ineficientes políticas educacionais dos últimos anos, aos escassos programas de accountability, à rigidez da estrutura educacional brasileira, entre outros. 
Tabela 13: Estatísticas descritivas da eficiência técnica por região

\begin{tabular}{|c|c|c|c|c|c|c|c|c|c|}
\hline \multicolumn{4}{|c|}{$4^{\mathrm{a}}$ série } & \multicolumn{6}{|c|}{$8^{\mathrm{a}}$ série } \\
\hline \multicolumn{10}{|c|}{ Norte } \\
\hline Ano & Média & Desvio Padrão & Mínimo & Máximo & Média & Desvio Padrão & Mínimo & Máximo & $\mathbf{N}$ \\
\hline 2007 & 1,09 & 0,09 & 0,80 & 1,40 & 1,06 & 0,07 & 0,81 & 1,53 & 5806 \\
\hline 2009 & 1,08 & 0,09 & 0,63 & 1,46 & 1,03 & 0,07 & 0,71 & 1,44 & 5806 \\
\hline 2011 & 1,06 & 0,10 & 0,78 & 1,65 & 1,02 & 0,07 & 0,78 & 1,41 & 5806 \\
\hline 2013 & 1,08 & 0,12 & 0,72 & 1,85 & 1,01 & 0,07 & 0,70 & 1,37 & 5806 \\
\hline \multicolumn{10}{|c|}{ Nordeste } \\
\hline 2007 & 1,14 & 0,11 & 0,82 & 1,67 & 1,10 & 0,08 & 0,76 & 1,48 & 10562 \\
\hline 2009 & 1,13 & 0,11 & 0,74 & 1,57 & 1,06 & 0,07 & 0,76 & 1,45 & 10562 \\
\hline 2011 & 1,08 & 0,11 & 0,77 & 1,62 & 1,05 & 0,08 & 0,77 & 1,35 & 10562 \\
\hline 2013 & 1,10 & 0,13 & 0,69 & 1,70 & 1,02 & 0,05 & 0,87 & 1,22 & 10562 \\
\hline \multicolumn{10}{|c|}{ Sudeste } \\
\hline 2007 & 1,03 & 0,09 & 0,68 & 1,79 & 1,02 & 0,07 & 0,77 & 1,52 & 12806 \\
\hline 2009 & 1,01 & 0,10 & 0,72 & 1,47 & 0,99 & 0,07 & 0,73 & 1,34 & 12806 \\
\hline 2011 & 0,99 & 0,09 & 0,76 & 1,40 & 0,98 & 0,07 & 0,74 & 1,30 & 12806 \\
\hline 2013 & 0,98 & 0,09 & 0,69 & 1,45 & 0,98 & 0,07 & 0,75 & 1,38 & 12806 \\
\hline \multicolumn{10}{|c|}{ Sul } \\
\hline 2007 & 1,04 & 0,08 & 0,80 & 1,55 & 1,03 & 0,07 & 0,83 & 1,53 & 3647 \\
\hline 2009 & 1,03 & 0,10 & 0,79 & 1,43 & 1,00 & 0,07 & 0,78 & 1,40 & 3647 \\
\hline 2011 & 1,00 & 0,09 & 0,71 & 1,53 & 0,99 & 0,07 & 0,81 & 1,46 & 3647 \\
\hline 2013 & 1,00 & 0,09 & 0,73 & 1,32 & 0,98 & 0,07 & 0,81 & 1,46 & 3647 \\
\hline \multicolumn{10}{|c|}{ Centro-Oeste } \\
\hline 2007 & 1,06 & 0,08 & 0,83 & 1,32 & 1,03 & 0,06 & 0,87 & 1,24 & 3109 \\
\hline 2009 & 1,04 & 0,09 & 0,75 & 1,42 & 1,01 & 0,06 & 0,79 & 1,26 & 3109 \\
\hline 2011 & 1,02 & 0,09 & 0,76 & 1,45 & 1,00 & 0,06 & 0,82 & 1,25 & 3109 \\
\hline 2013 & 1,01 & 0,08 & 0,80 & 1,39 & 1,01 & 0,06 & 0,82 & 1,25 & 3109 \\
\hline
\end{tabular}


Tabela 14: Estatísticas descritivas da eficiência gerencial por região

\begin{tabular}{|c|c|c|c|c|c|c|c|c|c|}
\hline \multicolumn{4}{|c|}{$4^{\mathrm{a}}$ série } & \multicolumn{6}{|c|}{$8^{\mathrm{a}}$ série } \\
\hline \multicolumn{10}{|c|}{ Norte } \\
\hline Ano & Média & Desvio Padrão & Mínimo & Máximo & Média & Desvio Padrão & Mínimo & Máximo & $\mathbf{N}$ \\
\hline 2007 & 0,60 & 0,03 & 0,53 & 0,73 & 0,68 & 0,03 & 0,56 & 0,93 & 58060 \\
\hline 2009 & 0,60 & 0,03 & 0,51 & 0,71 & 0,68 & 0,03 & 0,55 & 0,92 & 58060 \\
\hline 2011 & 0,60 & 0,03 & 0,54 & 0,86 & 0,68 & 0,03 & 0,60 & 0,83 & 58060 \\
\hline 2013 & 0,60 & 0,04 & 0,50 & 1,00 & 0,68 & 0,03 & 0,56 & 0,88 & 58060 \\
\hline \multicolumn{10}{|c|}{ Nordeste } \\
\hline 2007 & 0,62 & 0,03 & 0,52 & 0,86 & 0,69 & 0,03 & 0,60 & 0,91 & 10562 \\
\hline 2009 & 0,62 & 0,03 & 0,53 & 0,77 & 0,69 & 0,03 & 0,58 & 0,90 & 10562 \\
\hline 2011 & 0,61 & 0,03 & 0,53 & 0,85 & 0,69 & 0,03 & 0,61 & 0,84 & 10562 \\
\hline 2013 & 0,61 & 0,04 & 0,50 & 0,92 & 0,68 & 0,02 & 0,64 & 0,76 & 10562 \\
\hline \multicolumn{10}{|c|}{ Sudeste } \\
\hline 2007 & 0,60 & 0,02 & 0,51 & 0,94 & 0,68 & 0,02 & 0,60 & 0,95 & 12806 \\
\hline 2009 & 0,59 & 0,02 & 0,52 & 0,77 & 0,68 & 0,03 & 0,58 & 0,84 & 12806 \\
\hline 2011 & 0,60 & 0,02 & 0,53 & 0,73 & 0,68 & 0,03 & 0,58 & 0,83 & 12806 \\
\hline 2013 & 0,59 & 0,02 & 0,52 & 0,73 & 0,68 & 0,03 & 0,59 & 0,88 & 12806 \\
\hline \multicolumn{10}{|c|}{ Sul } \\
\hline 2007 & 0,61 & 0,02 & 0,55 & 0,78 & 0,69 & 0,03 & 0,63 & 1,00 & 36470 \\
\hline 2009 & 0,61 & 0,02 & 0,55 & 0,74 & 0,69 & 0,03 & 0,62 & 0,94 & 36470 \\
\hline 2011 & 0,59 & 0,02 & 0,52 & 0,79 & 0,68 & 0,03 & 0,62 & 0,97 & 36470 \\
\hline 2013 & 0,60 & 0,02 & 0,54 & 0,69 & 0,68 & 0,03 & 0,62 & 0,97 & 36470 \\
\hline \multicolumn{10}{|c|}{ Centro-Oeste } \\
\hline 2007 & 0,60 & 0,02 & 0,55 & 0,69 & 0,68 & 0,02 & 0,62 & 0,76 & 31090 \\
\hline 2009 & 0,60 & 0,02 & 0,54 & 0,75 & 0,68 & 0,02 & 0,61 & 0,77 & 31090 \\
\hline 2011 & 0,60 & 0,02 & 0,54 & 0,75 & 0,68 & 0,02 & 0,62 & 0,77 & 31090 \\
\hline 2013 & 0,60 & 0,02 & 0,55 & 0,70 & 0,67 & 0,02 & 0,62 & 0,77 & 31090 \\
\hline
\end{tabular}

Fonte: Elaborado pelos autores com base nos microdados da Prova Brasil e do Censo Escolar/INEP. 


\subsection{Eficiência Técnica e Não Discricionariedade}

Tal como apresentado no relatório Coleman et al. (1966), muitos estudos têm revelado a importância do background familiar como principal responsável pelas desigualdades nos resultados educacionais, restando muito pouco espaço para as escolas atuarem. Nesse sentido, a Tabela 15 apresenta a associação entre as variáveis não discricionárias e a medida de eficiência técnica para a $4^{\text {a }}$ série e a $8^{\text {a }}$ série, dado a importância do ambiente familiar dos alunos como determinante educacional, apontado na literatura por Leon \& Menezes-Filho (2002), Afonso \& Aubyn (2005), Afonso \& Aubyn (2006), Soares \& Collares (2006), entre outros. É também necessário conhecer a magnitude da influência de tais variáveis para a composição do escore de eficiência pelo fato de o gestor escolar não ter controle sobre tais fatores. Isso permite exprimir a real capacidade dos administradores escolares em atuar na melhoria da gestão de recursos.

Tabela 15: Estimativas das variáveis nãodiscricionárias

\begin{tabular}{|c|c|c|}
\hline Variáveis & $4^{\mathrm{a}}$ série & $8^{\mathrm{a}}$ série \\
\hline Homem & $\begin{array}{c}0,0469^{* * *} \\
(0,0074)\end{array}$ & $\begin{array}{l}0,0346^{* * *} \\
(0,0052)\end{array}$ \\
\hline Branco & $\begin{array}{l}0,0031 \\
(0,0070)\end{array}$ & $\begin{array}{c}-0,0327^{* * *} \\
(0,0037)\end{array}$ \\
\hline Idade & $\begin{array}{l}0,0589^{* * * *} \\
(0,0028)\end{array}$ & $\begin{array}{c}0,0444^{* * *} \\
(0,0015)\end{array}$ \\
\hline Mãe & $\begin{array}{r}-0,0099 \\
(0,0130)\end{array}$ & $\begin{array}{c}-0,0192^{* *} \\
(0,0084)\end{array}$ \\
\hline Mãe com superior & $\begin{array}{c}0,0199^{* * *} \\
(0,0073)\end{array}$ & $\begin{array}{l}0,0464^{* * *} \\
(0,0067)\end{array}$ \\
\hline Socioeconômico & $\begin{array}{l}0,1870^{* * * *} \\
(0,0222)\end{array}$ & $\begin{array}{l}0,2340^{* * * *} \\
(0,0094)\end{array}$ \\
\hline Incentivo escolar & $\begin{array}{l}0,1980^{* * *} \\
(0,0266)\end{array}$ & $\begin{array}{l}0,0434^{* *} \\
(0,0179)\end{array}$ \\
\hline Creche & $\begin{array}{c}-0,0164^{* * *} \\
(0,0053)\end{array}$ & $\begin{array}{l}0,0141^{* * * *} \\
(0,0026)\end{array}$ \\
\hline 2009 & $\begin{array}{c}-0,0319^{* * *} \\
(0,0022)\end{array}$ & $\begin{array}{l}0,0328^{* * *} \\
(0,0025)\end{array}$ \\
\hline 2011 & $\begin{array}{c}-0,0193^{* * * *} \\
(0,0024)\end{array}$ & $\begin{array}{c}-0,0459^{* * * *} \\
(0,0025)\end{array}$ \\
\hline 2013 & $\begin{array}{c}-0,0131^{* * *} \\
(0,0029)\end{array}$ & $\begin{array}{c}-0,0664^{* * * *} \\
(0,0028)\end{array}$ \\
\hline Constante & $\begin{array}{l}0,6800^{* * *} \\
(0,0415)\end{array}$ & $\begin{array}{c}0,5050^{* * *} \\
(0,0337)\end{array}$ \\
\hline Observações & 36600 & 35900 \\
\hline$R^{2}$ & 0,3102 & 0,3178 \\
\hline Wald & $\begin{array}{c}1238,3800 \\
(0,0000)\end{array}$ & $\begin{array}{c}6144,7200 \\
(0,0000)\end{array}$ \\
\hline \multicolumn{3}{|c|}{$\begin{array}{l}\text { Nota: Para a } 4^{\text {a }} \text { série estimou-se um modelo de efeitos } \\
\text { fixos; para a } 8^{\text {a }} \text { série, um modelo de efeitos aleatórios. } \\
\text { Nota: Os desvios-padrão foram obtidos por bootstrap } \\
\text { com } 1000 \text { replicações. } \\
\text { Nota: }{ }^{*} p<0,1,{ }^{* *} p<0,05,{ }^{* *} p<0,01 \text {. } \\
\text { Fonte: Elaborado pelos autores com base nos } \\
\text { microdados da Prova Brasil e do Censo Escolar/INEP. }\end{array}$} \\
\hline
\end{tabular}

De acordo com as estimativas, ser do sexo masculino e ter mãe com ensino superior contribui positivamente para o aumento da eficiência das escolas, apesar do baixo coeficiente das variáveis para os dois níveis de ensino. Isso se deve ao fato da maior presença de alunos do sexo feminino, que apresentam 
desempenho superior ao dos homens, e do baixo percentual de mães de alunos com nível superior na amostra, o que reduz a magnitude de tais variáveis. A idade do aluno também está positivamente relacionada a eficiência técnica, dado que o acúmulo de conhecimento evolui naturalmente com a idade, se refletindo em um melhor resultado na Prova Brasil. As estatísticas descritivas já mencionadas comprovam esse ponto, verificando uma maior nota média nas provas de Língua Portuguesa e Matemática para a $8^{\mathrm{a}}$ série vis-à-vis a $4^{\mathrm{a}}$ série.

Com relação aos alunos que moram com a mãe, o coeficiente não apresenta significância estatística para os alunos da $4^{\text {a }}$ série; para a $8^{a}$ série sua estimativa é negativa. Já para os alunos que iniciaram seus estudos na creche, observa-se um coeficiente negativo para a $4^{\mathrm{a}}$ série e positivo para a $8^{\mathrm{a}}$ série. A baixa qualidade da creche pode estar relacionada ao impacto negativo na fase inicial da vida escolar, piorando o desempenho dos alunos nos resultados dos testes padronizados. Por outro lado, esse efeito creche perde força com o passar do tempo, tornando-se positivo para a fase final do ensino fundamental, contribuindo para um maior escore de eficiência técnica.

O índice socioeconômico e de incentivo dos pais são as duas variáveis que apresentaram maior associação no aumento do escore de eficiência técnica. Para o índice socioeconômico, o coeficiente de 0,18 para a $4^{\text {a }}$ série e 0,23 para a $8^{a}$ série evidencia a importância das condições financeiras familiares no suporte à evolução do desempenho educacional dos filhos, mesmo quando estes já são mais velhos. O aparato da família permite aos filhos terem acesso a bens e informação que de outro modo não seria possível, além de poderem se dedicar somente a escola, não necessitando, por exemplo, trabalhar ou realizar outras tarefas que comprometam o rendimento escolar (Soares \& Collares 2006). Quanto ao envolvimento dos pais, é observado uma relação muito maior para a $4^{\text {a }}$ série, dado que são crianças mais novas e consequentemente mais dependentes dos pais, além de provavelmente reagirem com maior intensidade aos incentivos recebidos. A literatura recente sobre retornos educacionais já tem evidenciado que o envolvimento dos pais com a vida escolar dos filhos tem um resultado maior quando mais cedo esse investimento é realizado, além de potencializar o desempenho individual dos alunos (Cunha et al. 2010).

Por fim, foram inseridas variáveis dummy para os anos em que as escolas foram analisadas, tendo como base o ano de 2007 (primeiro ano da amostra). Os coeficientes negativos para os anos de 2009, 2011 e 2013 corroboram com as evidências anteriores de que a eficiência vem caindo ao longo do tempo, seja por uma piora na qualidade do sistema educacional ou por uma maior utilização de recursos, sem o devido retorno esperado.

\subsection{Determinantes da Eficiência Gerencial}

As Tabelas 16 e 17 reportam as estimativas dos determinates dos diferentes níveis de eficiência das escolas. Conforme explanado anteriormente, maior atenção foi dada à análise das variáveis que refletem o grau de autonomia gerencial das escolas na alocação dos seus recursos.

$\mathrm{Na} 4^{\text {a }}$ série (Tabela 16), com relação ao processo de escolha do gestor, as escolas menos eficientes obtêm uma redução nos seus escores de eficiência quando o diretor é selecionado pela própria comunidade escolar. À medida que se avança na distribuição de eficiência, o impacto dessa variável é não significativo, ou seja, as escolas que têm autonomia quanto à seleção dos seus 
gestores não apresentam diferença significativa de eficiência em comparação com as escolas cujo diretor é indicado por órgão externo.

As estimativas para as demais variáveis seguem essa mesma tendência de comportamento, indicando que a autonomia gerencial das escolas não desempenha papel relevante na determinação da eficiência gerencial da escola. $\mathrm{O}$ fato de o conselho escolar se reunir mais de três vezes ao ano reduziu sensivelmente os níveis de eficiência em todos os quantis analisados. A elaboração do projeto pedagógico pela própria escola reduz pontualmente a eficiência das escolas nos menores quantis, não apresentando efeito significativo nos quantis superiores. A seleção dos livros didáticos quando realizada pela própria escola gera um aumento significante na eficiência das escolas em todos os quantis. Isso se deve, possivelmente, aos efeitos positivos sobre o rendimento escolar dos alunos, uma vez que a comunidade escolar conhece melhor as necessidades de aprendizagem dos alunos e, assim, consegue escolher os livros que melhor atendem a essa demanda.

Tabela 16: Estimativas da relação entre eficiência gerencial e autonomia escolar $-8^{\text {a }}$ série

\begin{tabular}{|c|c|c|c|c|}
\hline Variáveis & $\tau=0,25$ & $\tau=0,5$ & $\tau=0,75$ & $\tau=0,9$ \\
\hline Diretoria & $\begin{array}{l}0,001^{* *} \\
(0,000)\end{array}$ & $\begin{array}{l}0,002^{* *} \\
(0,001)\end{array}$ & $\begin{array}{l}0,001^{* *} \\
(0,000)\end{array}$ & $\begin{array}{l}0,002^{* *} \\
(0,001)\end{array}$ \\
\hline Conselho & $\begin{array}{l}0,000 \\
(0,001)\end{array}$ & $\begin{array}{l}0,000 \\
(0,001)\end{array}$ & $\begin{array}{l}0,001^{* *} \\
(0,001)\end{array}$ & $\begin{array}{l}0,001^{* *} \\
(0,001)\end{array}$ \\
\hline Projeto & $\begin{array}{r}-0,001 \\
(0,002)\end{array}$ & $\begin{array}{r}-0,001 \\
(0,002)\end{array}$ & $\begin{array}{l}0,000 \\
(0,002)\end{array}$ & $\begin{array}{r}-0,001 \\
(0,003)\end{array}$ \\
\hline Admissão & $\begin{array}{c}-0,001^{* *} \\
(0,001)\end{array}$ & $\begin{array}{c}-0,001^{* *} \\
(0,001)\end{array}$ & $\begin{array}{c}-0,001^{* *} \\
(0,001)\end{array}$ & $\begin{array}{c}-0,001^{* *} \\
(0,002)\end{array}$ \\
\hline Interferência & $\begin{array}{c}-0,001^{* * *} \\
(0,001)\end{array}$ & $\begin{array}{l}0,000 \\
(0,001)\end{array}$ & $\begin{array}{l}0,000 \\
(0,001)\end{array}$ & $\begin{array}{l}0,000 \\
(0,001)\end{array}$ \\
\hline Livro & $\begin{array}{l}0,006^{* *} \\
(0,001)\end{array}$ & $\begin{array}{l}0,006^{* *} \\
(0,001)\end{array}$ & $\begin{array}{l}0,005^{* *} \\
(0,001)\end{array}$ & $\begin{array}{l}0,005^{* *} \\
(0,001)\end{array}$ \\
\hline Apoio & $\begin{array}{c}-0,002^{* * *} \\
(0,001)\end{array}$ & $\begin{array}{c}-0,001^{* *} \\
(0,001)\end{array}$ & $\begin{array}{c}-0,002^{* *} \\
(0,001)\end{array}$ & $\begin{array}{c}-0,002^{* * *} \\
(0,002)\end{array}$ \\
\hline Homogeneidade idade & $\begin{array}{l}0,002^{* *} \\
(0,001)\end{array}$ & $\begin{array}{l}0,002 \\
(0,003)\end{array}$ & $\begin{array}{l}0,002^{* *} \\
(0,001)\end{array}$ & $\begin{array}{l}0,002^{* *} \\
(0,001)\end{array}$ \\
\hline Homogeneidade rendimento & $\begin{array}{c}-0,004^{* *} \\
(0,000)\end{array}$ & $\begin{array}{c}-0,005^{* *} \\
(0,001)\end{array}$ & $\begin{array}{c}-0,005^{* * *} \\
(0,001)\end{array}$ & $\begin{array}{c}-0,005^{* * *} \\
(0,002)\end{array}$ \\
\hline Heterogeneidade idade & $\begin{array}{c}-0,002^{* *} \\
(0,003)\end{array}$ & $\begin{array}{c}-0,001 \\
(0,003)\end{array}$ & $\begin{array}{c}-0,002^{* * *} \\
(0,002)\end{array}$ & $\begin{array}{c}-0,002^{* * *} \\
(0,001)\end{array}$ \\
\hline Heterogeneidade rendimento & $\begin{array}{c}-0,001^{* *} \\
(0,002)\end{array}$ & $\begin{array}{c}-0,001^{* *} \\
(0,003)\end{array}$ & $\begin{array}{c}-0,001^{* *} \\
(0,002)\end{array}$ & $\begin{array}{c}-0,001^{* * *} \\
(0,001)\end{array}$ \\
\hline 2009 & $\begin{array}{c}-0,002^{* * *} \\
(0,001)\end{array}$ & $\begin{array}{c}-0,001^{* *} \\
(0,001)\end{array}$ & $\begin{array}{c}-0,002^{* * *} \\
(0,001)\end{array}$ & $\begin{array}{c}-0,002^{* * *} \\
(0,001)\end{array}$ \\
\hline 2011 & $\begin{array}{c}-0,001^{* *} \\
(0,001)\end{array}$ & $\begin{array}{l}0,000 \\
(0,001)\end{array}$ & $\begin{array}{c}-0,001^{* *} \\
(0,001)\end{array}$ & $\begin{array}{c}-0,002^{\text {*** }} \\
(0,001)\end{array}$ \\
\hline 2013 & $\begin{array}{l}0,002^{* *} \\
(0,001)\end{array}$ & $\begin{array}{l}0,001 \\
(0,002)\end{array}$ & $\begin{array}{l}0,000 \\
(0,002)\end{array}$ & $\begin{array}{l}0,000 \\
(0,002)\end{array}$ \\
\hline
\end{tabular}

Nota: Os desvios padrão foram obtidos por bootstrap com 1000 replicações. Nota: ${ }^{*} p<0,1,{ }^{* *} p<0,05,{ }^{* * *} p<0,01$.

Nota: Os valores de $c$ para os quantis $\tau=0,25, \tau=0,5, \tau=0,75$ e $\tau=0$, 9 são $0,226,0,456,0,725$ e 0,881 , respectivamente.

Fonte: Elaborado pelos autores com base nos microdados da Prova Brasil e do Censo Escolar/INEP.

A interferência externa na gestão do diretor aumenta a eficiência das escolas que já apresentam baixa eficiência e não é significativa para as escolas com maiores níveis de eficiência. Em suma, é possível inferir que embora as escolas menos eficientes demandem um maior grau de intervenção externa no seu funcionamento, esse fator apresentou uma baixa relevância para uma maior 
eficiência escolar.

$\mathrm{O}$ apoio da comunidade ao modelo de funcionamento da escola gerou um impacto negativo nas escolas menos eficientes. Quando as decisões do gestor são referendadas pela comunidade, abre-se margem para o fortalecimento das suas atuações, as quais podem reforçar o estado de ineficiência da escola.

Tabela 17: Estimativas da relação entre eficiência gerencial e autonomia escolar - $8^{\mathrm{a}}$ série

\begin{tabular}{|c|c|c|c|c|}
\hline Variáveis & $\tau=0,25$ & $\tau=0,5$ & $\tau=0,75$ & $\tau=0,9$ \\
\hline Diretoria & $\begin{array}{l}0,001^{* *} \\
(0,000)\end{array}$ & $\begin{array}{l}0,002^{* *} \\
(0,001)\end{array}$ & $\begin{array}{l}0,001^{* *} \\
(0,000)\end{array}$ & $\begin{array}{l}0,002^{* *} \\
(0,001)\end{array}$ \\
\hline Conselho & $\begin{array}{l}0,000 \\
(0,001)\end{array}$ & $\begin{array}{l}0,000 \\
(0,001)\end{array}$ & $\begin{array}{l}0,001^{* *} \\
(0,001)\end{array}$ & $\begin{array}{l}0,001^{* *} \\
(0,001)\end{array}$ \\
\hline Projeto & $\begin{array}{r}-0,001 \\
(0,002)\end{array}$ & $\begin{array}{r}-0,001 \\
(0,002)\end{array}$ & $\begin{array}{l}0,000 \\
(0,002)\end{array}$ & $\begin{array}{r}-0,001 \\
(0,003)\end{array}$ \\
\hline Admissão & $\begin{array}{c}-0,001^{* *} \\
(0,001)\end{array}$ & $\begin{array}{c}-0,001^{* *} \\
(0,001)\end{array}$ & $\begin{array}{c}-0,001^{* *} \\
(0,001)\end{array}$ & $\begin{array}{r}-0,001 \\
(0,002)\end{array}$ \\
\hline Interferência & $\begin{array}{c}-0,001^{* *} \\
(0,001)\end{array}$ & $\begin{array}{l}0,000 \\
(0,001)\end{array}$ & $\begin{array}{l}0,000 \\
(0,001)\end{array}$ & $\begin{array}{l}0,000 \\
(0,001)\end{array}$ \\
\hline Livro & $\begin{array}{l}0,006^{* *} \\
(0,001)\end{array}$ & $\begin{array}{l}0,006^{* *} \\
(0,001)\end{array}$ & $\begin{array}{l}0,005^{* *} \\
(0,001)\end{array}$ & $\begin{array}{l}0,005^{* *} \\
(0,001)\end{array}$ \\
\hline Apoio & $\begin{array}{c}-0,002^{* * *} \\
(0,001)\end{array}$ & $\begin{array}{c}-0,001^{* * *} \\
(0,001)\end{array}$ & $\begin{array}{c}-0,002^{* *} \\
(0,001)\end{array}$ & $\begin{array}{c}-0,002^{* * *} \\
(0,002)\end{array}$ \\
\hline Homogeneidade idade & $\begin{array}{l}0,002^{* * *} \\
(0,001)\end{array}$ & $\begin{array}{l}0,002 \\
(0,003)\end{array}$ & $\begin{array}{l}0,002^{* *} \\
(0,001)\end{array}$ & $\begin{array}{l}0,002^{* *} \\
(0,001)\end{array}$ \\
\hline Homogeneidade rendimento & $\begin{array}{c}-0,004^{* * *} \\
(0,000)\end{array}$ & $\begin{array}{c}-0,005^{* *} \\
(0,001)\end{array}$ & $\begin{array}{c}-0,005^{* *} \\
(0,001)\end{array}$ & $\begin{array}{c}-0,005^{* * *} \\
(0,002)\end{array}$ \\
\hline Heterogeneidade idade & $\begin{array}{c}-0,002^{* * *} \\
(0,003)\end{array}$ & $\begin{array}{r}-0,001 \\
(0,003)\end{array}$ & $\begin{array}{c}-0,002^{* *} \\
(0,002)\end{array}$ & $\begin{array}{c}-0,002^{* *} \\
(0,001)\end{array}$ \\
\hline Heterogeneidade rendimento & $\begin{array}{c}-0,001^{* *} \\
(0,002)\end{array}$ & $\begin{array}{c}-0,001^{* *} \\
(0,003)\end{array}$ & $\begin{array}{c}-0,001^{* *} \\
(0,002)\end{array}$ & $\begin{array}{c}-0,001^{* *} \\
(0,001)\end{array}$ \\
\hline 2009 & $\begin{array}{c}-0,002^{* *} \\
(0,001)\end{array}$ & $\begin{array}{c}-0,001^{* *} \\
(0,001)\end{array}$ & $\begin{array}{c}-0,002^{* *} \\
(0,001)\end{array}$ & $\begin{array}{c}-0,002^{* * *} \\
(0,001)\end{array}$ \\
\hline 2011 & $\begin{array}{c}-0,001^{* *} \\
(0,001)\end{array}$ & $\begin{array}{l}0,000 \\
(0,001)\end{array}$ & $\begin{array}{c}-0,001^{* *} \\
(0,001)\end{array}$ & $\begin{array}{c}-0,002^{* * *} \\
(0,001)\end{array}$ \\
\hline 2013 & $\begin{array}{l}0,002^{* * *} \\
(0,001)\end{array}$ & $\begin{array}{l}0,001 \\
(0,002)\end{array}$ & $\begin{array}{l}0,000 \\
(0,002)\end{array}$ & $\begin{array}{l}0,000 \\
(0,002)\end{array}$ \\
\hline
\end{tabular}

Nota: Os desvios padrão foram obtidos por bootstrap com 1000 replicações. Nota: ${ }^{*} p<0,1,{ }^{* *} p<0,05,{ }^{* * *} p<0,01$.

Nota: Os valores de $c$ para os quantis $\tau=0,25, \tau=0,5, \tau=0,75$ e $\tau=0,9$ são $0,226,0,456,0,725$ e 0,881 , respectivamente.

Fonte: Elaborado pelos autores com base nos microdados da Prova Brasil e do Censo Escolar/INEP.

Também foi analisada a relação entre a forma de alocação dos alunos nas turmas e a prática de gestão escolar. Nota-se que as escolas que alocaram seus alunos com base na homogeneidade quanto à idade apresentaram maiores escores de eficiência em todos os quantis da distribuição. Já quanto à heterogeneidade entre as idades, esse efeito se mostrou significante apenas para os menores quantis de eficiência. Com respeito ao desempenho dos alunos, percebe-se uma possível correlação com o grupo do qual o estudante faz parte, o chamado peer effect. Esse resultado é corroborado, em parte, pelo estudo de Lazear (2001), que propôs um modelo teórico para avaliar o efeito do peer effect sobre o desempenho dos alunos e demonstrou que a segregação dos alunos por nível de habilidade é a melhor forma de alocar os alunos. Para as escolas com maiores escores de eficiência os dois métodos de alocação dos alunos quanto ao rendimento geram os mesmos efeitos. É interessante observar que nos modelos em que se considera a presença de interações, como a incorporação dos peer effects nas funções de produção educacionais, as tomadas de 
decisão conduzem a equilíbrios descentralizados subótimos, o que permite a elaboração de políticas públicas (ou mecanismos de coordenação) que gerem ganhos de eficiência. Assim, percebe-se como as regras de alocação dos estudantes entre as turmas podem contribuir para o resultado global da escola em termos de eficiência gerencial.

Na $8^{a}$ série (Tabela 17), a autonomia das escolas desempenha um papel ainda menos relevante na determinação da eficiência escolar. A maioria das estimativas foi não significativa entre os quantis, como a atuação do conselho escolar, a autonomia sobre o projeto pedagógico e a interferência externa na administração da escola. O processo de seleção do diretor e a escolha dos livros didáticos feitos diretamente pela escola geraram ganhos de eficiência em todos os quantis. O apoio da comunidade às decisões do gestor mostrou-se negativo ao desempenho das escolas em termos de eficiência. De forma análoga ao que foi argumentado no caso da quarta série, isso pode reforçar decisões do gestor que possam gerar ineficiências na alocação dos recursos, uma vez que este se encontra respaldado pelo apoio da comunidade. Tanto a homogeneidade quanto a heterogeneidade com respeito à idade e ao rendimento na formação das turmas geraram perdas de eficiência em todos os quantis.

As variáveis dummy para os anos de 2009, 2011 e 2013 mostram como os escores de eficiência gerencial se comportam em relação ao ano base de 2007. Em 2009, nota-se uma redução dos escores em todos os quantis, na $4^{\mathrm{a}}$ e na $8^{\mathrm{a}}$ séries. Em 2013 os escores de eficiência para a $4^{\text {a }}$ série tiveram uma evolução positiva e significante, enquanto que na $8^{a}$ série não se percebe mudanças significantes na eficiência das escolas.

\section{Considerações Finais}

Este trabalho teve por objetivo mensurar a eficiência das escolas públicas brasileiras na alocação dos seus recursos e os fatores determinantes do seu grau de eficiência. A partir da técnica não paramétrica order- $\alpha$, calcularam-se os escores de eficiência técnica das escolas e posteriormente foi descontada a influência de variáveis não discricionárias, isto é, aquelas não diretamente relacionadas à escola, tal como o background familiar. Com isso tem-se a medida de eficiência ajustada, levando em consideração influência de variáveis escolares sobre as medidas de eficiência robustas. Dado que as variáveis não afetam de forma semelhante a gestão de cada escola, a metodologia empregada tem a vantagem de levar em conta a heterogeneidade não observada entre as escolas.

Depois de encontrado os escores de eficiência ajustados, foi utilizado um modelo de dados em painel em um contexto de regressão quantílica, para avaliar qual a influência das características das escolas sobre os diversos níveis de eficiência da gestão escolar. A relevância do presente estudo surge com o fato de que apesar do crescimento dos recursos e de reformas na organização e gestão nas últimas décadas, as deficiências do sistema educacional brasileiro ainda persistem, sobretudo no tocante à qualidade da educação. Para cumprir o objetivo proposto utilizaram-se os microdados da Prova Brasil para os anos de 2007, 2009, 2011 e 2013, sendo a escola a unidade básica de análise.

Observou-se que houve poucas melhorias nos resultado dos testes padronizados e piora nas taxas de aprovação. Ao mesmo tempo verificou-se uma piora do conjunto de recursos disponíveis às escolas. Essa combinação resultou em uma deterioração das práticas de gestão dos administradores locais, ou 
seja, o balanceamento ótimo entre os recursos escolares e os produtos a serem maximizados não foi o principal objetivo dos diretores.

Com relação às variáveis não discricionárias, os resultados corroboram as evidências presentes na literatura sobre a importância do background familiar e das condições socioeconômicas para o desempenho escolar dos alunos. Um aluno cujos pais possuem alta escolaridade e estimulam as suas habilidades cognitivas, tende a ter maiores resultados nas proficiências, que, por sua vez, impactam positivamente nos níveis de eficiência escolar.

No tocante aos determinantes da eficiência gerencial, os resultados da estimação quantílica evidenciaram que a autonomia gerencial das escolas se mostra pouco relevante para a determinação do grau de eficiência. Esse resultado surge como contraponto à tese sustentada pelo relatório da OCDE na qual escolas com maior autonomia na alocação dos seus recursos tendem a elevar o desempenho educacional dos estudantes.

Diante do que foi exposto pelo presente artigo, é notória a necessidade de políticas públicas que visem melhorar a gestão escolar, dado o descompasso entre os recursos disponíveis e o desempenho educacional. Portanto, mais do que mensurar os níveis de eficiência, este estudo buscou compreender quais os fatores que determinam o desempenho das escolas nesse critério, de forma a contribuir para a formulação de políticas mais específicas para o setor educacional.

\section{Referências Bibliográficas}

Afonso, A. \& Aubyn, M. S. (2005), 'Non-parametric approaches to education and health efficiency in OECD countries', Journal of Applied Economics 8(2), 227-246.

Afonso, A. \& Aubyn, M. S. (2006), 'Cross-country efficiency of secondary education provision: a semi-parametric analysis with non-discretionary inputs', Economic Modelling 23(3), 476-491.

Afonso, A. \& Fernandes, S. (2008), 'Assessing and explaining the relative efficiency of local government', The Journal of Socio-Economics 37(5), 19461979.

Afonso, A., Schuknecht, L. \& Tanzi, V. (2010), 'Public sector efficiency: evidence for new EU member states and emerging markets', Applied Economics 42(17), 2147-2164.

Aigner, D. J. \& Chu, S.-F. (1968), 'On estimating the industry production function', American Economic Review 58(4), 826-839.

Aigner, D., Lovell, C. K. \& Schmidt, P. (1977), 'Formulation and estimation of stochastic frontier production function models', Journal of Econometrics 6(1), 21-37.

Almeida, A. \& Gasparini, C. (2011), 'Gastos públicos municipais e educação fundamental na Paraíba: uma avaliação usando DEA', Revista Econômica do Nordeste 42(3).

Aragon, Y., Daouia, A. \& Thomas-Agnan, C. (2005), 'Nonparametric frontier estimation: a conditional quantile-based approach', Econometric Theory 21(02), 358-389. 
Banco Mundial (2001), 'Brazil early child development: a focus on the impact of preschools', Relatório n. 22851 - BR.

Banker, R. D. \& Natarajan, R. (2008), 'Evaluating contextual variables affecting productivity using data envelopment analysis', Operations Research 56(1), 48-58.

Barros, R. P. d., Carvalho, M. d., Franco, S., Mendonça, R. \& Rosalém, A. (2011), 'Uma avaliação do impacto da qualidade da creche no desenvolvimento infantil', Pesquisa e Planejamento Econômico 41(2), 213-232.

Carvalho, L. D. B. d. \& Sousa, M. d. C. S. d. (2014), 'Eficiência das escolas públicas urbanas das regiões Nordeste e Sudeste do Brasil: uma abordagem em três estágios', Estudos Econômicos (São Paulo) 44(4), 649-684.

Castano, M. C. N. \& Cabanda, E. C. (2007), 'Performance evaluation of the efficiency of Philippine Private Higher Educational Institutions: application of frontier approaches', International Transactions in Operational Research 14(5), 431-444.

Castro, C. d. M. \& Fletcher, P. (1986), 'A escola que os brasileiros freqüentaram em 1985', IPEA/IPLAN.

Cazals, C., Florens, J.-P. \& Simar, L. (2002), 'Nonparametric frontier estimation: a robust approach', Journal of Econometrics 106(1), 1-25.

Charnes, A., Cooper, W. W. \& Rhodes, E. (1978), 'Measuring the efficiency of decision making units', European Journal of Operational Research 2(6), 429 444.

Cherchye, L., De Witte, K., Ooghe, E. \& Nicaise, I. (2010), 'Efficiency and equity in private and public education: a nonparametric comparison', European Journal of Operational Research 202(2), 563-573.

Chernozhukov, V. \& Hong, H. (2011), 'Three-step censored quantile regression and extramarital affairs', Journal of the American Statistical Association 97(459), 872-882.

Clements, B. (2002), 'How efficient is education spending in Europe?', European Review of Economics and Finance 1(1), 3-26.

Coleman, J. S., Campbell, E. Q., Hobson, C. J., McPartland, J., Mood, A. M., Weinfeld, F. D. \& York, R. (1966), Equality of educational opportunity, in R. Arum, I. Beattie \& K. Ford, eds, 'The Structure of Schooling: Readings in the Sociology of Education', Vol. 1, Pine Forge Press.

Cunha, F., Heckman, J. J. \& Schennach, S. M. (2010), 'Estimating the technology of cognitive and noncognitive skill formation', Econometrica 78(3), 883931.

Daouia, A. \& Ruiz-Gazen, A. (2006), 'Robust nonparametric frontier estimators: qualitative robustness and influence function', Statistica Sinica 16(4), 1233-1253. 
Daraio, C. \& Simar, L. (2007), Advanced Robust and Nonparametric Methods in Efficiency Analysis: Methodology and Applications, Vol. 4, 1 edn, Springer US, New York.

Delgado, V. M. S. \& Machado, A. F. (2007), 'Eficiência das escolas públicas estaduais de Minas Gerais', Pesquisa e Planejamento Econômico 37(3), 427464.

Deprins, D., Simar, L. \& Tulkens, H. (1984), Measuring labor-efficiency in post offices, in M. Marchand, P. Pestieau \& H. Tulkens, eds, 'The Performance of Public Enterprises: Concepts and Measurement', North-Rolland.

Farenzena, N. (2005), Custos e Condições de Qualidade da Educação em Escolas Públicas: Aportes de Estudos Regionais, 1 edn, INEP, Ministério da Educação, Brasília.

Faria, F. P., Jannuzzi, P. d. M. \& Silva, S. d. (2008), 'Eficiência dos gastos municipais em saúde e educação: uma investigação através da análise envoltória no estado do Rio de Janeiro', Revista de Administração Pública 42(1), 155-177.

Fried, H. O., Lovell, C. K., Schmidt, S. S. \& Yaisawarng, S. (2002), 'Accounting for environmental effects and statistical noise in data envelopment analysis', Journal of Productivity Analysis 17(1-2), 157-174.

Gonçalves, F. d. O. \& França, M. T. A. (2013), 'Eficiência na provisão de educação pública municipal: uma análise em três estágios dos municípios brasileiros', Estudos Econômicos 43(2), 271-299.

Gramani, M. C. N. \& Duarte, A. L. d. C. M. (2011), 'O impacto do desempenho das instituições de educação básica na qualidade do ensino superior', Revista Ensaio: Avaliação e Políticas Públicas em Educação 19(72), 679-702.

Greene, W. H. (1993), The econometric approach to efficiency analysis, in H. Fried, C. A. K. Lovell \& P. Schimdt, eds, 'The Measurement of Productive Efficiency and Productivity Growth', Oxford University Press New York.

Gupta, S. \& Verhoeven, M. (2001), 'The efficiency of government expenditure: experiences from Africa', Journal of Policy Modeling 23(4), 433-467.

Hanushek, E. A. (1986), 'The economics of schooling: production and efficiency in public schools', Journal of Economic Literature 24(3), 1141-1177.

Hanushek, E. A. \& Luque, J. A. (2003), 'Efficiency and equity in schools around the world', Economics of Education Review 22(5), 481-502.

Hanushek, E. A. \& Woessmann, L. (2008), 'The role of cognitive skills in economic development', Journal of Economic Literature 46(3), 607-668.

Hattie, J. (2009), Visible learning: a synthesis of over 800 meta-analyses relating to achievement, 1 edn, Routledge, New York.

Lazear, E. P. (2001), 'Education production', Quarterly Journal of Economics 96(3), 777-802.

Leon, F. L. L. d. \& Menezes-Filho, N. A. (2002), 'Reprovação, avanço e evasão escolar no Brasil', Pesquisa e Planejamento Econômico 32(32). 
Machado, D. C., Gonzaga, G. \& Firpo, S. P. (2013), 'A relação entre proficiência e dispersão de idade na sala de aula: a influência do nível de qualificação do professor', Pesquisa e Planejamento Econômico 43(3), 419-445.

Machado Junior, S. P., Irffi, G. I. \& Benegas, M. B. B. (2011), 'Análise da eficiência técnica dos gastos com educação, saúde e assistência social dos municípios cearenses', Planejamento e Políticas Públicas 36, 87-113.

Marinho, A. \& Façanha, L. O. (1999), 'Instituições federais de ensino superior: modelos de financiamento e o incentivo à eficiência', Revista Brasileira de Economia 53(3), 357-386.

Marinho, A., Resende, M. \& Façanha, L. (1997), 'Brazilian federal universities: relative efficiency evaluation and data envelopment analysis', Revista Brasileira de Economia 51(4), 489-508.

Niitsuma, H. \& Okada, T. (2005), Covariance and PCA for categorical variables, in T. B. Ho, D. Cheung \& H. Liu, eds, 'Advances in Knowledge Discovery and Data Mining', Springer.

OCDE (2011), 'School autonomy and accountability: are they related to student performance?', PISA in Focus.

Oliveira, V. R. d., Silva, A. C. A. d. \& de Farias Souza, W. P. S. (2015), 'Reexaminando o papel do background familiar: uma abordagem não-paramétrica', Anais do XVIII Encontro de Economia da Região Sul ANPEC Sul.

Ordine, P., Rose, G. \& Sposato, D. (2015), 'Early enrollees and peer age effect: first evidence from INVALSI data', Journal of Education and Training Studies $3(2), 70-82$.

Ruggiero, J. (1998), 'Non-discretionary inputs in data envelopment analysis', European Journal of Operational Research 111(3), 461-469.

Soares, J. F. \& Collares, A. C. M. (2006), 'Recursos familiares e o desempenho cognitivo dos alunos do ensino básico brasileiro', Dados - Revista de Ciências Sociais 49(3), 615-650.

Soares, S., Razo, R. \& Fariñas, M. (2006), Perfil estatístico da educação rural: origem socioeconômica desfavorecida, insumos escolares deficientes e resultados inaceitáveis, in A. M. Bof, ed., 'A Educação no Brasil Rural', INEP.

Sousa, M. d. C. S. d. \& Ramos, F. S. (1999), 'Eficiência técnica e retornos de escala na produção de serviços públicos municipais: o caso do Nordeste e do Sudeste brasileiros', Revista Brasileira de Economia 53(4), 433-461.

Thieme, C., Prior, D. \& Tortosa-Ausina, E. (2013), 'A multilevel decomposition of school performance using robust nonparametric frontier techniques', Economics of Education Review 32(4), 104-121.

Zoghbi, A. C., Mattos, E. M., Rocha, F. R. R. \& Arvate, P. A. (2011), 'Uma análise da eficiência nos gastos em educação fundamental para os municípios paulistas', Planejamento e Políticas Públicas 1(36), 9-61. 


\section{Apêndice A Algoritmo para o Cômputo da Eficiência}

Daraio \& Simar (2007) fornecem os passos para obter o estimador proposto na Equação (7):

1. Seja $\mathcal{M}_{y}=\sum_{i=1}^{N} \mathbf{I}\left(Y_{i} \geq y\right)$, em que I é uma função indicadora.

2. Defina $\mathcal{X}_{i}=\max _{k=1, \ldots, K} \frac{x_{i}^{k}}{x^{k}}, i=1, \ldots, N$.

3. Para $j=1, \ldots, \mathcal{M}_{y}$ denote por $\mathcal{X}_{(j)}^{y}$ a estatística de ordem $j$ das observações $\mathcal{X}_{i}$ tal que $Y_{i} \geq y: \mathcal{X}_{(1)}^{j} \leq \mathcal{X}_{(2)}^{j} \leq \ldots \leq \mathcal{X}_{\left(\mathcal{M}_{y}\right)}^{j}$.

4. A partir do passo 3 segue que a medida de eficiência é definida como:

$$
\widehat{\gamma}_{\alpha, i}^{\mathrm{OA}}= \begin{cases}\mathcal{X}_{\left((1-\alpha) \mathcal{M}_{y}\right)}, & \text { se }(1-\alpha) \mathcal{M}_{y} \in \mathbb{N} \\ \mathcal{X}_{\left(\left[(1-\alpha) \mathcal{M}_{y}\right]+1\right),} & \text { caso contrário }\end{cases}
$$

em que $\mathbb{N}$ é o conjunto dos números inteiros não negativos.

5. Repita o passo $4 R$ vezes para obter $A=\left\{\left(\widehat{\gamma}_{\alpha, i}^{O A^{*}}, \widehat{\sigma}_{\gamma}^{*}\right)_{r}\right\}_{r=1}^{R}$.

Para estimar o índice de eficiência como proposto em (7) é necessário escolher o $\alpha$ ótimo e, assim, reduzir o viés da medida de eficiência. Para detectar descontinuidades na amostra e determinar o valor ótimo de $\alpha$ sugere-se o seguinte algoritmo adaptado de Daouia \& Ruiz-Gazen (2006) e Daraio \& Simar (2007):

1. Compute para cada ponto $\left(X_{i}, Y_{i}\right), i=1, \ldots, N$, seu nível de eficiência orientado para os insumos em relação ao conjunto de referência. Denote por $\widehat{\gamma}_{\alpha, i}^{(i)}$ o escore de eficiência desse ponto e o correspondente conjunto de referência $\mathcal{X}^{(i)}$.

2. Calcule $\widehat{\gamma}_{\alpha, i}^{(i)}, i=1, \ldots, N$, para um conjunto razoável de valores de $\alpha$.

3. Compute também o número de pontos usados para estimar a seguinte função de distribuição condicional empírica:

$$
\begin{aligned}
\widehat{F}_{Y \mid X, i}(\gamma y \mid x) & =\frac{\sum_{i \mid Y_{i} \geq y} \mathbf{I}(\mathcal{X} \leq \gamma)}{\mathcal{M}_{y}}=\frac{\sum_{j=1}^{\mathcal{M}_{y}} \mathbf{I}\left(\mathcal{X}_{(j)}^{y} \leq \gamma\right)}{\mathcal{M}_{y}} \\
\# \text { pto } & =\left\{\begin{array}{lll}
0, & \text { se } \quad \gamma<\mathcal{X}_{(1)}^{y} \\
\frac{j}{\mathcal{M}_{y}}, & \text { se } \quad \mathcal{X}_{(j)}^{y} \leq \gamma<\mathcal{X}_{(j+1)}^{y} \\
1, & \text { se } \quad \gamma \geq \mathcal{X}_{\left(\mathcal{M}_{y}\right)}^{y}
\end{array}\right.
\end{aligned}
$$

isto é, o número de pontos no conjunto $\mathcal{X}^{(i)}$ com $y \geq Y_{i}$. Denote esse número como $N_{\text {input }}\left(X_{i}, Y_{i}\right)$. Se $N_{\text {input }}\left(X_{i}, Y_{i}\right)$ é menor ou igual a zero o ponto correspondente $\left(X_{i}, Y_{i}\right)$ está sobre a fronteira dos valores amostrais de $\mathcal{X}$. Portanto, $N_{\text {input }}\left(X_{i}, Y_{i}\right)$ indica o quanto o ponto $\left(X_{i}, Y_{i}\right)$ está próximo da fronteira de produção. 